
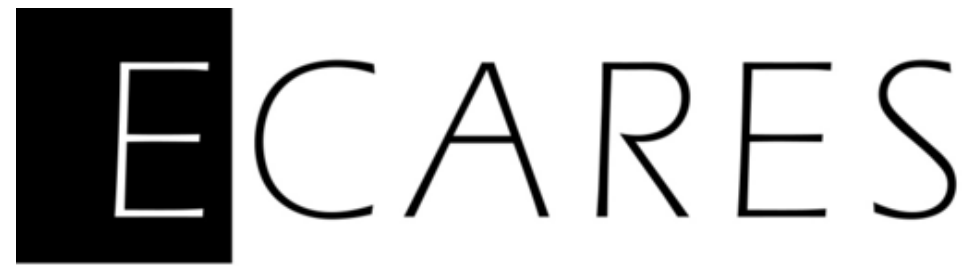

Incentives to (not) Disclose Energy Performance Information in the Housing Market

\author{
Elisabetta Cornago
}

SBS-EM, ECARES, Université libre de Bruxelles, FRS-FNRS

Luisa Dressler

SBS-EM, ECARES, Université libre de Bruxelles, FRS-FNRS

November 2018

ECARES working paper 2018-34

ECARES

ULB - CP $114 / 04$

50, F.D. Roosevelt Ave., B-1050 Brussels BELGIUM

www.ecares.org 


\title{
Incentives to (not) disclose energy performance information in the housing market ${ }^{\text {th }}$
}

\author{
Elisabetta Cornago ${ }^{\mathrm{a}}$, Luisa Dressler ${ }^{\mathrm{a}}$ \\ ${ }^{a}$ Université libre de Bruxelles, Solvay Brussels School of Economics and Management, ECARES and \\ FRS-FNRS.
}

\begin{abstract}
Disclosure of energy performance certificates (EPCs) is often incomplete, which hampers their effectiveness in relieving information asymmetries between landlords and tenants in the housing market. Even when a certificate is available, landlords do not always disclose it. This contradicts the unraveling result, according to which all landlords should disclose quality information unless it is costly to do so. We leverage a cross-sectional dataset of residential rental advertisements from the Belgian region of Brussels to empirically evaluate incentives to disclose an EPC. We find that two fundamental assumptions for the unraveling result are not confirmed in our setting: tenants value energy performance of rental property only when dwellings are of very high quality and do not appear to rationally adjust their expectations when faced with dwellings that withhold their EPC. The paper formulates specific policy advice for reforming EPC mechanisms to increase disclosure rates.
\end{abstract}

Keywords: Information Unraveling, Voluntary Information Disclosure, Asymmetric Information, Energy Efficiency, Certification

JEL codes: C21, D82, L15, Q48

\section{Introduction}

Energy performance certification is widely used in housing markets to overcome the informational asymmetries between buyers and sellers or tenants and landlords. The way such policies are implemented in practice varies: disclosing energy performance certificates (EPCs) is compulsory in some countries and voluntary in others. Even when disclosure is compulsory, enforcement may be lax. ${ }^{1}$

\footnotetext{
औ Both authors gratefully acknowledge financial support from the Belgian National Science Foundation (FNRS) and thank Immoweb and Institut Bruxellois pour la Gestion de l'Environnement for providing data. We are grateful to Jan Bouckaert, Estelle Cantillon, Anna Creti, Bram De Rock, Alexandros Dimitropoulos, Antonio Estache, Natalia Fabra, Meredith Fowlie, Louis-Gaëtan Giraudet, Sebastian Königs, Elisa Lanzi, Karsten Neuhoff, Nic Rivers and Joachim Schleich for very useful comments and discussion. We thank seminar participants at CIRED, ECARES, OECD and the audiences of AWEEE 2016 and EAERE 2016. A previous version of this paper was circulated with the title "The Rent Impact of Disclosing Energy Performance Certificates: Energy Efficiency and Information Effects".

Email addresses: elisabetta.co@gmail.com (Elisabetta Cornago), luisa.dressler@gmail.com (Luisa Dressler)

${ }^{1}$ For example, the European Union has made disclosure of energy performance certificates compulsory in rental and sales advertisements, but compliance is not strictly enforced across all member states and information disclosure has often been reported as incomplete and highly heterogeneous across member states (European Commission, 2015).
} 
A well-known result in microeconomic theory, the unraveling theorem (Milgrom, 1981; Grossman, 1981), implies that such policy variations are inconsequential when certification costs are low enough. When information disclosure is costless and verifiable, all owners will choose to disclose quality information of their housing unit at equilibrium, because not doing so will lead buyers or tenants to update downward their belief about its expected energy performance. In practice, however, there is evidence that disclosure of energy performance information is not complete as unraveling theories predict, particularly in rental markets (European Commission, 2015; Frondel et al., 2018; Bian and Fabra, 2018)

In this paper, we seek to understand reasons for low disclosure rates of EPCs in the rental market and explore disclosure incentives of landlords when disclosure is voluntary. This is critical as low disclosure rates hamper the effectiveness of EPCs in relieving information asymmetries.

We derive testable hypotheses to empirically verify whether the assumptions underlying the unraveling result hold in a setting where certification costs are sunk and disclosure is costless. ${ }^{2}$ The mechanism behind the unraveling result relies on two main assumptions. First, tenants value energy performance. Second, tenants hold rational expectations about undisclosed quality. This means that they update downward their beliefs about the energy performance of a housing unit whenever an EPC is not disclosed.

We empirically test these two assumptions using a novel dataset from the Belgian region of Brussels. First, we find evidence that the first assumption is only partially satisfied: energy performance is valued only for top performing housing units, which are rewarded with rent premiums relative to low performing counterparts. Second, we find that the second assumption is not satisfied: tenants do not appear to rationally adjust their expectations about energy performance when faced with housing units that withhold their EPC rating. More specifically, we find that tenants fail to reward those dwellings that disclose EPC ratings with a rent premium, which may directly affect landlords' disclosure incentives.

Compared to existing studies that analyze the impact of energy performance certification, we exploit a richer dataset and focus on a policy setting that allow us to directly study landlords' incentives to disclose or hide energy performance information and derive implications for the failure of the unraveling result.

A growing literature analyses the value associated with high energy performance signaled via EPCs in the commercial (Eichholtz et al., 2010) and the residential housing market in the United States (Kahn and Kok, 2014; Walls et al., 2017) and in Europe (Brounen and Kok, 2011; Hyland et al., 2013; Wahlström, 2016). Conversely, the reasons behind low disclosure of energy performance information have rarely been considered. As a consequence, disclosure incentives of sellers and owners are not fully understood. By way of exception, Frondel et al. (2018) and Olaussen et al. (2017) study the change in housing prices during a shift from a voluntary to a mandatory disclosure regime in Germany and Norway, while Bian and Fabra (2018) analyze how penalties for nondisclosure affect incentives to obtain and disclose certificates in Spain.

Our paper contributes to this literature by providing the first empirical analysis of

\footnotetext{
${ }^{2}$ Once a landlord has obtained an EPC, the transaction costs to put the certificate information in the rental advertisement are likely negligible. It reduces to simply filling in one additional piece of information in the same online template.
} 
disclosure incentives under voluntary rules when disclosure is costless. This provides an ideal setting to test the assumptions underlying the unraveling theorem. Our ability to study disclosure incentives comes from a unique feature in our data. We exploit a novel dataset of online rental advertisements, which enables us to observe a dwelling's EPC rating both when landlords disclose and when they hide it, conditional on the dwelling having been certified.

We analyze the case of the Belgian region of Brussels: although disclosure of EPCs was made compulsory by law in November 2011 (Gouvernement de la Région de BruxellesCapitale, 2011), it was de facto voluntary due to very loose regulatory enforcement in the period that we consider (2010-2014). Our data reveal that disclosure rates are low in our setting: even when their dwelling has been certified, at least $27 \%$ of landlords do not disclose its EPC rating in the rental ad.

Being able to differentiate between disclosed and undisclosed EPCs is crucial for our identification strategy. First, it enables us to estimate the pure informational value associated with disclosing a certificate, as opposed to hiding it. To the best of our knowledge, we are the first to identify this informational value. Second, this feature of our data enables us to obtain reliable estimates of the value that tenants associate with high energy performance, as it tells us whether tenants actually observe energy performance information at the moment of their search. We address two remaining identification challenges, a potential selection bias in the decision to disclose and endogeneity between rent and the disclosure decision, with a Heckman correction and an instrumental variable approach.

Understanding the reasons that drive the gap between the theoretical result of full unraveling and the empirical observation of incomplete disclosure is both an interesting theoretical question and relevant for policymakers. Enforcement of mandatory disclosure rules may be a costly means of achieving full information disclosure. Governments may grasp low-hanging fruits by reforming current EPC mechanisms and increase disclosure rates even under voluntary disclosure. On the basis of our analysis, we formulate policy recommendations to reform existing certification mechanisms to foster EPC disclosure.

The paper is structured as follows. In the next section we discuss the conceptual framework of the unraveling result and derive two testable hypotheses that may explain the failure of the unraveling result in our setting. Section 3 describes our context and data. We test and discuss the two hypotheses in Section 4 and 5. Section 6 closes with some final remarks and policy recommendations.

\section{Conceptual framework}

Information-based policies such as quality certification may solve the "lemons" problem of asymmetric quality information described by Akerlof (1970). A central prediction of information economics is the unraveling result: quality information of a good is voluntarily revealed in equilibrium for all quality levels in a context where disclosure is truthful and disclosure costs negligible (Milgrom, 1981; Grossman, 1981). In such a setting, a seller always has an incentive to disclose the most valuable quality information in order to separate from the pool of competitors with undisclosed (inferior) quality. If buyers rationally suspect withheld information to indicate low quality, the seller will also reveal the second most valuable quality, and so on until information unravels completely.

The unraveling result can be formalized as follows: consider a seller with some private information about the good's quality $\theta$, where $\theta \in[\underline{\theta}, \bar{\theta}]$. In a situation where prices 
are increasing in quality (conditional on quality being disclosed) and where disclosure is costless and truthful, a profit-maximizing seller will have an incentive to disclose quality and charge $p(\theta)$ as long as $p(\theta) \geq p(\mathbb{E}[\theta])$; that is when the price for disclosing quality information exceeds the price of expected (undisclosed) quality, $\mathbb{E}[\theta]$. In this case, not disclosing $\theta$ and charging a price of $p(\mathbb{E}[\theta])$ cannot be an equilibrium. If consumers hold rational expectations, they will update downward their belief about undisclosed quality such that, in equilibrium, they assume undisclosed quality is of the worst possible type, i.e. $\mathbb{E}[\theta]=\underline{\theta}$. As a consequence, information unravels completely: all sellers whose goods' quality level is above the market minimum, i.e. $\theta \geq \underline{\theta}$, will be disclosing quality information.

Energy performance certificates (EPCs) enable truthful information disclosure about the energy performance of housing units that can be verified ex-post. EPCs have been widely implemented to solve an asymmetric information problem in the housing market. While landlords are aware of the thermal quality of the dwelling they want to rent, it is complex for tenants to clearly infer this when screening the rental market. However, the theoretical result of full information unraveling is often not observed empirically when it comes to EPC disclosure in rental advertisements (European Commission, 2015; Frondel et al., 2018). As we further discuss in Section 3, our data suggests that EPC disclosure is also incomplete in the Belgian region of Brussels.

An explanation for incomplete EPC disclosure is that some assumptions at the heart of the unraveling result do not hold in the housing market. In the present analysis, we seek to test whether two of the main assumptions are confirmed in our context. ${ }^{3}$

One of the main assumptions behind full unraveling is that prices are increasing in quality, conditional on quality being disclosed. This assumption requires that consumers value quality and are willing to pay more for high-quality goods than for low-quality goods. Consider the case where consumers do not assign different values to goods of high and low quality. In such a case a seller will not be able to charge a higher price for high quality, $p(\bar{\theta})=p(\underline{\theta})=p(\theta)$, and has no incentive to disclose this type of information. In the housing market, if consumers do not value energy performance, information unraveling may break down. We test this assumption by examining whether energy performance is actually valued in our context, being reflected in higher rents.

Hypothesis 1. Consumers are willing to pay a positive premium for products of better quality compared to products of lower quality.

Consumers may not be willing to pay more for high (disclosed) quality for several reasons, leading to the failure of Hypothesis 1. For example, Fishman and Hagerty (2003) show that equilibria without full unraveling can arise if a fraction of consumers are unable to interpret a seller's disclosure (e.g. due to a lack of technical expertise and time or due to inattention). In their theoretical model, inexperienced or inattentive consumers observe a disclosed quality signal but are unable to derive its value. With regards to the housing market, interpreting energy performance information related to buildings can be challenging for at least two reasons. First, understanding the technical

\footnotetext{
${ }^{3}$ The potential failure of these two assumptions may interact and lead to behavior that is not discussed here. Further, several other factors may affect disclosure incentives and lead to partial unraveling, but not all are relevant in our context, such as costly disclosure as discussed in Jovanovic (1982). For a review of additional reasons that may limit information disclosure, see Dranove and Jin (2010).
} 
aspects of energy use and the complexity of the energy market is not trivial. Second, it may be difficult for consumers to evaluate the monetary savings which may derive from reduced energy consumption in housing units of better energy performance. ${ }^{4}$

The housing market is prone to further complicate the interpretation of quality information: acquiring experience about the impacts of different energy performance levels by living in different houses is not straightforward given low moving rates. Visiting housing units during the search process (as opposed to living there) does not always convey the necessary information about the implications of energy performance either.

Housing units are multidimensional rather than unidimensional, which can also affect quality information disclosure. Heterogeneous preferences for specific housing dimensions may explain why consumers value energy performance differently than in the setting described in the unraveling result. For example, some consumers may attribute lower importance to a housing unit's energy performance than to its other attributes. Finally, consumers with tight budget constraints may not be able to afford high energy performance, which affects their relative valuation of different housing attributes.

A second crucial assumption for the unraveling result is that consumers hold rational expectations about undisclosed quality. This means that, when quality information is not disclosed, they update downward their belief about the quality of a good. If beliefs about undisclosed quality are updated downward, a seller of a high-quality good will have an incentive to disclose this information to distinguish itself from the pool of competitors with undisclosed and expected lower quality.

While we cannot measure tenants' expectations directly in our framework, expectations about undisclosed energy performance will have implications for the difference between the rent of housing units that disclose energy performance information and those that hide it, which we do observe. We call this differential the "informational value" of EPCs.

More precisely, if tenants fail to update downwards their beliefs, the expected value of undisclosed energy performance may be relatively high. As a consequence, some landlords may prefer to pool with the goods of undisclosed quality to benefit from the high expected value, which will translate in higher rents. For example, a profitmaximizing landlord whose dwelling for rent has energy performance $\theta^{\prime}$ will not disclose an EPC as long as $p(\mathbb{E}[\theta])>p\left(\theta^{\prime}\right)$ : disclosing the energy performance rating would be associated with a rent that is lower than the rent of housing units that hide their rating. Hence, if the expected value associated to undisclosed energy performance is relatively high, the information unraveling may break down.

We test whether tenants in the Brussels rental market show rational expectations by estimating the informational value of EPCs. If the informational value of disclosing (as opposed to hiding) a certificate is positive, it underscores that tenants update their beliefs when faced with dwellings with undisclosed energy performance.

Hypothesis 2. When facing a product whose quality is not disclosed, consumers update downward their beliefs about its quality.

Consumers may not update their beliefs downwards as necessary for the unraveling result for different reasons: if that is the case, the rational expectations assumption is

\footnotetext{
${ }^{4}$ Cross-country surveys of different amplitude across selected OECD countries (OECD, 2014) and EU countries (European Commission, 2015) provide anecdotal evidence that attention to EPCs while searching for housing and understanding of their meaning are not widespread.
} 
unmet. Several theoretical studies and laboratory experiments offer insights that are directly transferable to the housing market.

Quality disclosure may be incomplete in equilibrium if consumers do not observe market transactions frequently enough to learn what undisclosed quality stands for and to update their expectations accordingly. While already Milgrom and Roberts (1986) mention that the full unraveling equilibrium may not be instantaneously achieved, Forsythe et al. (1989) show that full disclosure of quality information is the only sequential equilibrium in a sealed-bid auction model with costless disclosure. However, many more equilibria exist in a simple Bayesian Nash equilibrium context, for example equilibria where no quality is disclosed or where sellers only disclose information for some quality levels.

Key to full unraveling is the repeated nature of the game, as Forsythe et al. (1989) confirm in a laboratory experiment. Buyers that initially do not assume the worst about undisclosed quality, lower their expectation after they have observed the quality of each item. In their experiment, the unraveling process is already impeded if one single buyer is slow in adopting the assume-the-worst posture.

In the housing market, transactions are relatively infrequent as people rarely move between homes, so the mechanism to learn about undisclosed quality through observing (or experiencing) quality as described in the Forsythe et al. (1989) experiment is not necessarily verified.

Consumers may also fail to update their belief downward if considering only a subset of the available quality information. Using only a subset of the information to form expectations can be due to inattention as argued in Hirshleifer and Teoh (2003), or due to specificities of the market.

For example, in the housing market consumers generally do not observe the full distribution of disclosed EPCs to make inference about undisclosed quality, but know the energy performance information only for the sample of houses that they have screened or visited. In addition, as EPC disclosure is very partial, even after screening an ad or visiting a housing unit, a prospective tenant may likely not have observed an EPC. As a consequence, instead of updating downward their belief about undisclosed quality, there is some positive probability that a consumer's expectation of undisclosed quality is relatively high. This may lead landlords to hide quality information instead of disclosing it and take advantage of higher prices for undisclosed quality.

In a more recent laboratory experiment, Jin et al. (2015) confirm that consumers remain "insufficiently skeptical" about undisclosed information, which can lead to partial unraveling. The authors further test how different feedback types affects the understanding of missing information. While aggregate feedback about sellers' behavior (measured as the overall likelihood of disclosure for each quality level) does not improve quality inference by the consumer, immediate and direct feedback about the true quality of each transacted good can overcome the naïveté of consumers and achieve convergence with the unraveling result. We interpret this result as a sign that providing consumers with the full EPC distribution may still be insufficient to generate rational expectations, because it might be a too broad, aggregate piece of information to be integrated in their specific housing choices.

In a theoretical framework, Li et al. (2016) show that the presence of consumers who cannot reason about the behavior of sellers and who have biased prior beliefs will make disclosure of unfavorable information less likely. The authors discuss reasons for biased priors which potentially also occur in the housing market. These include unawareness, 
limited attention to a complex multi-attribute product, and limited-recall consumers.

Finally, Harbaugh and To (2005) show that withholding good news can be an equilibrium when there is coarse messaging, i.e. when the signal does not fully reveal the exact quality (which is the case for letter- or color-based indicators often used in EPCs). Having few partitions in the quality indicator may lead to non-disclosure because revealing good (but not top) quality may not be sufficiently impressive. Conversely, more granular quality indicators will lead to full unraveling in equilibrium. Applying this result to the housing market, however, implies a trade-off between reducing information granularity to help people digesting and understanding the energy performance indicator, and increasing the granularity to prompt information unraveling as per the authors' findings.

\section{Background and data}

\section{Brussels: an ideal setting to study EPC disclosure incentives}

We analyze EPC disclosure in residential rental advertisements in the Belgian region of Brussels between 2010 and 2014. In this period, the Brussels' residential rental housing market provides an ideal setting to test the hypotheses derived in Section 2 and to better understand landlords' disclosure incentives as well as the failure of the unraveling result.

First, disclosure of EPC information is de facto voluntary in that period. In November 2011, the Government of the region of Brussels introduced regulation making the disclosure of EPC ratings in sales or rental advertisements mandatory (Gouvernement de la Région de Bruxelles-Capitale, 2011). However, in this initial stage, compliance with legislation was not enforced towards individual landlords in Brussels. ${ }^{5}$ This lax enforcement correlates with very partial disclosure of EPC information: only $73 \%$ of the rental ads that previously have obtained an EPC also disclose the EPC rating. When considering all ads independently of whether an EPC was obtained or not, only $8 \%$ disclose the rating.

Figure A.2 in the Appendix gives an example of an EPC issued in Brussels. A housing unit's primary energy consumption is synthesized in a letter-based rating of energy performance, ranging from A to G. Color coding helps potential tenants or buyers to map letters into thermal quality indicators: high energy efficiency ratings (A, $\mathrm{B}, \mathrm{C})$ are associated with the color green, intermediate energy efficiency ratings (D, E) with orange and low efficiency ratings $(F, G)$ with red.

In Brussels, certificates are issued by official certifiers trained by the regional environmental agency, IBGE (Institut Bruxellois de Gestion de l'Environnement or Bruxelles Environnement). Certifiers estimate the primary energy consumption of a housing unit based on information gathered during a personal inspection and from homeowners' documents providing details on the dwelling's heating devices, air-conditioning, domestic hot water, ventilation, insulation and structure. Energy consumption from appliances is not considered in this evaluation. If detailed documents are unavailable, certifiers base their assessment on default values from several housing features (IBGE, 2013). Certificate prices are not regulated; certifying an apartment can cost a minimum of about 150 euros, with the price increasing in the size of the dwelling.

\footnotetext{
${ }^{5}$ Some random compliance checks started only in late 2013 and were directed solely at real estate agencies rather than the private segment of the market (European Commission, 2015).
} 
A second characteristic of our set-up lends support to testing the assumptions underlying the unraveling result: disclosure is costless conditional on certification. Thanks to a unique feature in our dataset, we focus our analysis on a subset of the residential market, namely housing units that have been certified in the first place. Thus, certification costs are sunk. Because we observe whether an EPC that has been obtained is eventually disclosed or hidden from the rental advertisement, we are able to focus on the pure disclosure decision of a landlord, independently on the decision to obtain certification. This is a welcoming feature when testing assumptions of the unraveling result. ${ }^{6}$

\section{Data sources}

We have obtained data on rental advertisements from Belgium's main selling and letting property website, Immoweb, which is "by far the most important online portal of real estate in Belgium" according to the Belgian competition authority. ${ }^{7}$

The dataset contains detailed information about all 200,290 rental homes that were advertised on Immoweb's platform from January 2010 to September 2014, covering all 19 municipalities in the region of Brussels. ${ }^{8}$ It includes the advertised rent, the exact publication date of the ad, the EPC rating if disclosed (9,885 ads), and a large set of characteristics that are likely to directly affect the value of the dwelling: municipality where the housing unit is located, size (e.g. total surface and number of rooms), age of the building, and some indicators of comfort (e.g. presence of garden, balcony, elevator, furniture). All of the advertisement and dwelling features that we exploit in the analysis are described in Table B.6 of the Appendix.

We follow the literature and consider the advertised rent corresponds with the rent ultimately agreed upon and written in the rental contract. The market for housing in the region of Brussels is tight. As discussed by Dessouroux et al. (2016), housing demand is excessive and the expansion of the housing offer has been insufficient in Brussels. This leaves only limited room for tenants to bargain on rents, so that the difference between the asked price observed in our data and the rent that is ultimately paid is likely minimal.

Our dataset has the advantage that we observe when a landlord has previously obtained a certificate but omits to indicate the actual rating in the ad. We call these ads with hidden EPC ratings. More precisely, some Immoweb rental ads signal the certificate ID but not the obtained EPC rating. Matching the certificate ID of rental ads hiding an EPC to the official EPC registry allows us to retrieve the (hidden) EPC rating of 3,701 dwellings. ${ }^{9}$

\footnotetext{
${ }^{6}$ Other analyses do the opposite and focus intentionally on the combined effect, i.e. the decision to obtain a certificate and to disclose it (Bian and Fabra, 2018).

${ }^{7}$ See Paragraph 24 of Decision ABC-2016-I/O-31-AUD of 7 November 2016, available at https://www.bma-abc.be/sites/default/files/content/download/files/161107_ abc-2016-io-31-aud_pub.pdf.

${ }^{8}$ We have excluded from the dataset rentals of rooms in shared apartments, as well as outliers with respect to rent and surface values.

${ }^{9}$ The official EPC registry contains information on all certificates issued in Brussels since the launch of the certification scheme for residential buildings. For each certified dwelling, the registry reports the actual EPC rating, certificate number, location and other dwelling features. It is maintained by the regional environmental agency managing the EPC mechanism, IBGE.
} 
Finally, we use data from the regional statistical institute, IBSA (Institut Bruxellois de Statistique et d'Analyse), to control for characteristics of the location of advertised dwellings in our regression analysis. For this, we use data on time-varying socio-economic statistics measured at municipality level, such as population and office density, average income, unemployment rates, quality of schools and public transport. All socio-economic variables used in the analysis are described in Table B.7 of the Appendix.

The subsample of rental advertisements that hide or disclose an EPC rating (13,586 observations) represents the main dataset that we use throughout the analysis. We call compliers those ads that disclose an EPC rating and non-compliers those that hide it.

\section{Descriptive statistics}

Table 1 provides evidence that EPC disclosure is incomplete and varies with the energy performance level among housing units conditional on being certified. ${ }^{10}$ In particular, it shows that EPC disclosure increases with energy performance: the odds for a landlord to disclose an EPC are higher for housing units of high quality, while the odds for hiding increase when the EPC indicates low energy performance. Disclosure drops from $100 \%$ to just over $66 \%$ as the EPC rating goes from A to $\mathrm{G}$.

Table 1: Disclosure rate among certified housing units, by EPC rating

\begin{tabular}{c|c|c|c}
\hline \hline EPC rating & $\begin{array}{c}\text { Ads with } \\
\text { disclosed EPC } \\
(N=9,885)\end{array}$ & $\begin{array}{c}\text { Ads with } \\
\text { hidden EPC } \\
(N=3,701)\end{array}$ & $\begin{array}{c}\text { Disclosure } \\
\text { rate }\end{array}$ \\
\hline $\mathrm{A}$ & 36 & 0 & $100 \%$ \\
$\mathrm{~B}$ & 415 & 61 & $87.2 \%$ \\
$\mathrm{C}$ & 2,326 & 671 & $77.6 \%$ \\
$\mathrm{D}$ & 2,854 & 1,072 & $72.7 \%$ \\
$\mathrm{E}$ & 2,162 & 837 & $72.1 \%$ \\
$\mathrm{~F}$ & 953 & 482 & $66.4 \%$ \\
$\mathrm{G}$ & 1,139 & 578 & $66.3 \%$ \\
\hline \hline
\end{tabular}

Relating this observation to the discussion of the unraveling theorem presented in Section 2, full information disclosure is confirmed only for the top of the quality distribution: landlords disclose the most valuable quality information (A rating) to distinguish themselves from the pool of competitors. However, information unraveling breaks down for quality levels below top quality: less and less information is disclosed as quality decreases. In the remainder of this analysis, we seek to understand to what extent this observation can be linked to a failure of two central assumptions for the theoretical result of complete disclosure.

Table 2 provides descriptive statistics for the ads with disclosed EPCs and with hidden EPCs. On average, dwellings whose EPC rating is disclosed in the rental ad are larger than their counterparts with hidden EPCs by 13 sqm. Likewise, they tend to be associated with a higher rent per square meter.

Of dwellings with hidden EPC ratings, $74 \%$ have access to open spaces (i.e. terraces, balconies and gardens), while this is the case for $77 \%$ of ads that instead disclose the

\footnotetext{
${ }^{10}$ The disclosure rate unconditional on whether a certificate has been obtained or not, i.e. relative to the total number of rental ads is plotted in Figure A.3 in the Appendix.
} 
Table 2: Descriptive statistics: main variables

\begin{tabular}{|c|c|c|c|c|}
\hline & \multicolumn{2}{|c|}{$\begin{array}{c}\text { Ads with } \\
\text { disclosed EPC } \\
(\mathrm{N}=9,885)\end{array}$} & \multicolumn{2}{|c|}{$\begin{array}{c}\text { Ads with } \\
\text { hidden EPC } \\
(\mathrm{N}=3,701)\end{array}$} \\
\hline & Mean & Std.Dev. & Mean & Std.Dev. \\
\hline Real rent (2010 euros) & 1106.9 & 577.61 & 881.97 & 441.75 \\
\hline Real rent per sqm (2010 euros) & 10.62 & 2.64 & 9.75 & 2.45 \\
\hline Dwelling surface (sqm) & 107.39 & 53.54 & 94.38 & 45.56 \\
\hline Dwelling type: house (prop.) & 0.07 & 0.25 & 0.05 & 0.22 \\
\hline \multicolumn{5}{|l|}{$\begin{array}{r}\text { Dwelling features } \\
\text { (proportion) }\end{array}$} \\
\hline Access to open space & 0.77 & 0.42 & 0.74 & 0.44 \\
\hline Garage/parking & 0.19 & 0.39 & 0.27 & 0.44 \\
\hline Lift & 0.13 & 0.34 & 0.25 & 0.43 \\
\hline Luxury & 0.01 & 0.11 & 0.01 & 0.09 \\
\hline Fully/partly furnished & 0.23 & 0.42 & 0.11 & 0.31 \\
\hline Brand new/renovated & 0.25 & 0.43 & 0.25 & 0.43 \\
\hline Equipped kitchen & 0.18 & 0.38 & 0.18 & 0.38 \\
\hline \multicolumn{5}{|l|}{ Ad features (proportion) } \\
\hline Short-term contract possible & 0.01 & 0.09 & 0.00 & 0.06 \\
\hline Real estate agency rental & 0.06 & 0.24 & 0.04 & 0.20 \\
\hline Multilingual ad & 0.28 & 0.45 & 0.52 & 0.50 \\
\hline $\begin{array}{r}\text { Year of construction } \\
(\text { proportion) }\end{array}$ & \multicolumn{2}{|c|}{$(\mathrm{N}=4,506)$} & \multicolumn{2}{|c|}{$(\mathrm{N}=1,647)$} \\
\hline Before 1900 & 0.01 & 0.09 & 0.02 & 0.13 \\
\hline 1900-1919 & 0.04 & 0.20 & 0.07 & 0.26 \\
\hline $1920-1944$ & 0.09 & 0.29 & 0.14 & 0.35 \\
\hline $1945-1969$ & 0.14 & 0.35 & 0.21 & 0.41 \\
\hline $1970-1984$ & 0.09 & 0.29 & 0.14 & 0.34 \\
\hline $1985-2000$ & 0.11 & 0.31 & 0.07 & 0.25 \\
\hline After 2000 & 0.51 & 0.49 & 0.36 & 0.48 \\
\hline
\end{tabular}

rating. Ads with hidden EPCs tend to be more often associated with facilities such as lifts or garage and parking spots. The proportion of dwellings which have been recently built or renovated is the same across the two subsets $(25 \%)$, as is the proportion of dwellings with a fully equipped kitchen (18\%). Ads disclosing an EPC rating are more likely to be partly or fully furnished.

Less than half of the ads with EPCs (hidden or disclosed) signal the dwelling's year of construction (6153 ads). Among ads with disclosed EPCs, $51 \%$ of the dwellings they propose for rent are located in buildings that were recently built, i.e. after year 2000 . This proportion is $36 \%$ across ads with a hidden EPC.

The proportion of rentals proposed by real estate agencies is $6 \%$ in both subsamples: this shows that this web platform is used primarily by private homeowners to rent their goods without the mediation of third parties such as agencies

\section{The valuation of energy performance: testing Hypothesis 1}

Disclosing EPC information to prospective tenants during their search is critical to overcome the information asymmetry about energy performance and enable fully informed choices. However, as described in Table 1, landlord's in Brussels often hide 
EPCs even if a certificate has been obtained. This observation contradicts the unraveling theorem, according to which all quality levels should be disclosed in equilibrium when disclosure costs are negligible.

In this section we test whether one of the central assumptions underlying the unraveling result is actually fulfilled in the present context. Hypothesis 1 requires that consumers are willing to pay a positive premium for products of better quality compared to products of lower quality. In other words, Hypothesis 1 implies that tenants value energy performance, which makes disclosure beneficial for landlords, thereby directly affecting their incentives to disclose. To test this hypothesis, we build an hedonic price model, with the aim of inferring the valuation of a dwelling's different attributes, including energy performance, by observing its overall rent.

$$
\log \left(p_{i}\right)=\alpha+\text { EPCrat }_{\mathbf{i}} \beta+\mathbf{X}_{\mathbf{i}} \gamma+\mathbf{A}_{\mathbf{i}} \kappa+\mathbf{M}_{\mathbf{i}} \delta+\mathbf{Z}_{\mathbf{i}} \zeta+\epsilon_{i}
$$

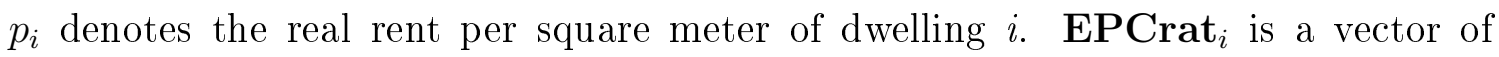
dummies representing a dwelling's energy performance rating, ranging from A to G. $\mathbf{X}_{\mathbf{i}}$ is a vector of dwelling characteristics, such as number of rooms, year of construction, dwelling type. $\mathbf{A}_{\mathbf{i}}$ is a vector of advertisement characteristics, such as whether an ad is multilingual or whether it has been posted by a real estate agency rather than by a private homeowner. $\mathbf{M}_{\mathbf{i}}$ is a vector of time-varying socio-economic variables measured at the municipality level, such as density, average income, school capacity. ${ }^{11} \mathbf{Z}_{\mathbf{i}}$ captures municipality dummies, to control for a dwelling's location, as well as month dummies and a year trend to control for seasonality relative to the advertisement's date of publication. $\epsilon_{i}$ is the i.i.d. error term.

\subsection{Empirical strategy}

To verify whether Hypothesis 1 holds in our context, we estimate the rental value that is associated to different levels of energy performance, conditional on the rating being disclosed (sample of compliers). We are interested in understanding whether dwellings with high energy performance, earn a rent premium relative to comparable dwellings with inferior energy performance. The EPC rating is used as a proxy for a dwellings' energy performance. By focusing on the sample of compliers, we ensure that quality information is actually available to all prospective tenants and can be capitalized into rents.

However, comparing the distributions in the two central columns of Table 1 suggests, that selection into the conditional sample of compliers does not occur randomly. EPC ratings indicating low energy performance (ratings between $\mathrm{F}$ and $\mathrm{G}$ ) are more often hidden, while EPC ratings indicating high energy performance (between A and C) are relatively more often disclosed. Our results confirm this intuition.

Non-random sample selection is a problem if unobservable characteristics affecting outcome (i.e. a dwelling's rent) are correlated with unobservable characteristics affecting selection into the data (i.e. the decision to disclose an EPC rating). In such a case, estimating the effect of the EPC rating on rent by ordinary least squares (OLS) would lead to biased estimates. The Heckman selection model enables us to control for the bias from non-random selection (Wooldridge, 2010).

\footnotetext{
${ }^{11}$ The full set of dwelling-level control variables and municipality-level control variables is reported respectively in Table B.6 and B.7 in the Appendix.
} 
We apply the selection model as follows. We estimate the outcome equation specified above, while accounting for the fact that the EPC disclosure decision might be a function of a non-random selection process. The selection equation relates the decision to disclose an EPC to the same observed characteristics as included in equation (1):

$$
\operatorname{Pr}\left(\operatorname{Disc}_{i}=1\right)=\Phi\left(\alpha+\eta E R_{i}+\mathbf{E P C r a t}_{\mathbf{i}} \mathbf{d} \mu+\mathbf{X}_{\mathbf{i}} \psi+\mathbf{A}_{\mathbf{i}} \theta+\mathbf{M}_{\mathbf{i}} \xi+\mathbf{Z}_{\mathbf{i}} \phi\right)
$$

$\Phi(\cdot)$ is the standard normal cumulative distribution function. Disc is a dummy variable: it takes the value 1 when a rental advertisement discloses the energy performance rating of dwelling $i$; conversely, it takes the value of 0 when the rating is undisclosed. The rationale for the exclusion restriction $E R_{i}$ is explained in detail below. The same control variables included in the outcome equation (1) are also included in this equation.

As typical in this literature, we assume that the errors in the hedonic and the selection equation are jointly normally distributed. We obtain consistent parameter estimates by maximum likelihood. The log likelihood function to be maximized combines the different likelihood functions both for compliers and non-compliers, dwellings disclosing and hiding their EPC rating. ${ }^{12}$

The Heckman model allows us to test for non-random selection in our sample. Rejecting the hypothesis of a zero correlation between the error terms $\left(H_{0}: \rho=0\right.$, where $\left.\rho=\operatorname{corr}\left(u_{i}, \epsilon_{i}\right)\right)$ suggests that selection into the sample of compliers does not occur randomly and that a simple OLS regression would yield biased estimates.

Identification. To correctly identify our selection process, we include an exogenous determinant of disclosure of EPC ratings as exclusion variable in the selection equation (2). We use the share of votes for green parties in the Brussels municipalities (greenvote) as an exclusion restriction. A particular appeal of this variable comes from its variation over time and geographical area.

This indicator is constructed using information on votes for both the French-speaking (Ecolo) and the Dutch-speaking (Groen) green party during four elections across the 19 municipalities in the region of Brussels. The following election dates are used: 7 June 2009 (election of the regional Parliament), 13 June 2010 (federal elections), 14 October 2012 (election of municipality Councils) and 25 May 2014 (elections of the regional Parliament). We assume that the share of votes remains constant between the date at which an election takes place and the next election. Votes in 2009 and 2010 are available by electoral canton (regrouping some municipalities). Votes in 2012 and 2014 are available at the municipality level. Figure 1 describes how the share of votes for the green parties varies over time and geographic area in the region of Brussels.

A valid exclusion restriction needs to fulfill two conditions. It should significantly affect the selection probabilities (relevance condition), i.e. the decision to disclose an EPC rating as modelled in the selection equation (2), while not directly influencing outcome (exogeneity condition), i.e. the rent in our hedonic regression (1).

With respect to the first condition, we argue that inhabitants of municipalities with an important vote share for green parties are relatively more aware of environmental issues and related policies, including the EPC regulation. We claim that the higher environmental awareness of tenants translates into increased pressure on landlords to

\footnotetext{
${ }^{12}$ The likelihood function of the $i^{\text {th }}$ observation in the group of compliers is represented by the probability of the joint event $p_{i}$ and $D i s c_{i}=1$. The likelihood function of the $i^{\text {th }}$ observation in the group of non-compliers is the marginal probability that $\operatorname{Disc}_{i}=0$.
} 
Figure 1: Time and geographic variation in greenvote across the region of Brussels

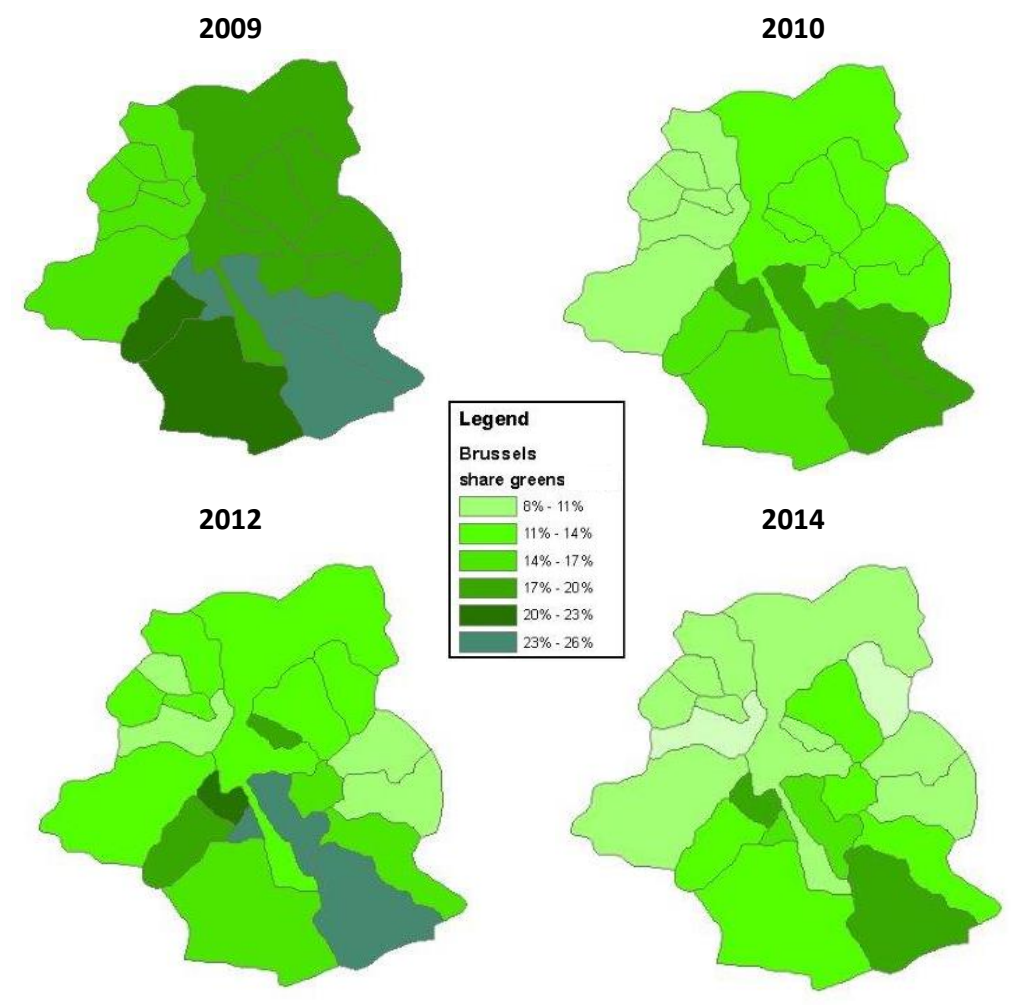

disclose EPC ratings in rental advertisements. ${ }^{13}$ Our claim is confirmed by the data. Results from estimating different models of selection equation (2) show a positive and statistically significant coefficient on the variable of interest: the share of green votes is a relevant driver of EPC disclosure in our sample. Results for these regressions are discussed and displayed in Table D.8 in the Appendix.

With respect to the second condition, we argue that the vote share for green parties is excluded from the outcome equation and influences rent only indirectly via EPC disclosure. Simple calculations show that the correlation between average real rent per square meter and greenvote is low in the sample of compliers, 0.14. Exogeneity of our instrument is improved, because we control for a large set of other factors that may affect both rents and the share of votes for green parties, such as municipality-level average income per capita, access to public transport (which green voters might prefer to private car use) as well as municipality fixed effects (a municipality with numerous parks might be likelier to attract green residents).

\footnotetext{
${ }^{13}$ One may argue that increased environmental awareness of tenants will also push landlords towards hiding red EPCs relatively more often. However, we could not find an indication for this pattern: the correlation between greenvote and the proportion of hidden EPC ratings per month and municipality (i.e. the share of rentals hiding their EPC rating out of all rentals in our sample) is negative $(-0.41)$, and stronger for low than for high values of greenvote. For example, cutting the sample of compliers at the median of greenvote shows that this correlation is three times stronger in the sub-sample below the median than in the above-median sub-sample.
} 


\subsection{Results}

Within the Heckman selection model, we estimate by maximum likelihood the average treatment effect of different EPC ratings on the rent of housing units, conditional on the EPC rating being disclosed (compliers). The estimation allows us to assess whether tenants are willing to pay a positive premium for better energy performance in Brussels (Hypothesis 1), while ensuring that energy performance information is actually available to all prospective tenants. Table 3 presents results for the estimation of the outcome equation (1). Results for the estimation of the selection equation are reported in Table D.9 in the Appendix.

We report coefficients for the main variables and for four different specifications. All specifications use the natural logarithm of real rent per square meter as dependent variable. ${ }^{14}$ We report only the main regressor which is a factor variable indicating the level of energy performance as conveyed to tenants in the disclosed EPC. In the first two specifications, EPC ratings are aggregated in three color-based categories: green (B and $\mathrm{C}$ ), orange (D and $\mathrm{E}$ ) and red ( $\mathrm{F}$ and $\mathrm{G}$ ), with the red category being the baseline. In the other specifications, letter-based EPC ratings are reported, and the baseline is a G-rated EPC. ${ }^{15}$

We control for a large set of dwelling and contract attributes that are included in the rental advertisement (e.g. number of bedrooms, surface), as well as for variables indicating dwelling quality (i.e. its renovation status, presence of white goods) and proxies for the quality of the rental advertisement (e.g. the availability of the ad in different languages, ${ }^{16}$ the number of words used in the description of a dwelling). An exhaustive explanation of all control variables used in the regression is reported in Table B.6. The coefficient from the estimation related to these variables in the outcome equation are reported in Table D.10.

All specifications include municipality dummies to control for geographical variation in rent, as well as month dummies and a yearly time trend to account for seasonal effects and region-wide factors affecting rent variation in time. We also include time-varying socio-economic variables measured at municipality level: Table B.7 in the Appendix lists all socio-economic variables used in the analysis. Their coefficients are reported in Table D.11. Robust standard errors are reported in parentheses. ${ }^{17}$

\footnotetext{
${ }^{14}$ Nominal rent is adjusted for inflation using the monthly consumer price index in Belgium. The base month is January 2010. Data source: Belgium Directorate-General Statistics.

${ }^{15}$ Given there are only 36 A-rated dwellings in the sample, which fully disclose their EPC rating, they have been excluded from the analysis.

${ }^{16}$ We interpret the publication of an ad in multiple languages (i.e. French, English and/or Dutch) as a measure of quality, indicating that a landlord aims at increasing the accessibility of the rental to a broader audience. However, it could also capture an expat effect, meaning a landlord taking advantage of foreigners who are relatively rich compared to the Belgian average (e.g. employees at the European institutions) but not always fluent in French or Dutch.

${ }^{17}$ Clustering robust standard errors within certain geographical agglomerations is common whenever unobserved determinants of outcomes are correlated within clusters. However, municipality-level clustered standard errors are not appropriate in the present context. As indicated by Abadie et al. (2017), clustered standard errors should be adopted in the presence of cluster-level sampling design or experimental design issues. This means that clustered standard errors should be adopted if a subset of municipalities were sampled randomly from the population of municipalities in the region of Brussels, and subsequently, rental ads were sampled randomly from the sampled municipalities: this is not the case in our dataset, where all municipalities are represented. Alternatively, clustered standard errors should be adopted if assignment to the treatment (in our case, EPC regulation) is correlated within
} 
Table 3: The valuation of energy performance (outcome equation).

\begin{tabular}{|c|c|c|c|c|}
\hline & (1) & $(2)$ & $(3)$ & $(4)$ \\
\hline & \multicolumn{4}{|c|}{ Log(real rent/sqm) } \\
\hline \multicolumn{5}{|l|}{ Color categories } \\
\hline Green EPC & $\begin{array}{c}0.069^{* * *} \\
(0.005)\end{array}$ & $\begin{array}{c}0.037^{* * *} \\
(0.010)\end{array}$ & & \\
\hline Orange EPC & $\begin{array}{c}0.019^{* * *} \\
(0.005)\end{array}$ & $\begin{array}{c}0.010 \\
(0.008)\end{array}$ & & \\
\hline \multicolumn{5}{|l|}{ Letter categories } \\
\hline $\mathrm{B}$ & & & $\begin{array}{c}0.081^{* * *} \\
(0.010)\end{array}$ & $\begin{array}{c}0.052^{* * *} \\
(0.016)\end{array}$ \\
\hline $\mathrm{C}$ & & & $\begin{array}{c}0.057^{* * *} \\
(0.007)\end{array}$ & $\begin{array}{c}0.020 \\
(0.012)\end{array}$ \\
\hline $\mathrm{D}$ & & & $\begin{array}{l}0.017^{* *} \\
(0.006)\end{array}$ & $\begin{array}{c}0.001 \\
(0.012)\end{array}$ \\
\hline $\mathrm{E}$ & & & $\begin{array}{c}0.003 \\
(0.007)\end{array}$ & $\begin{array}{l}-0.006 \\
(0.012)\end{array}$ \\
\hline $\mathrm{F}$ & & & $\begin{array}{c}-0.018^{* *} \\
(0.007)\end{array}$ & $\begin{array}{l}-0.026^{*} \\
(0.014)\end{array}$ \\
\hline \multicolumn{5}{|l|}{ Construction year } \\
\hline Construction $1900-20$ & & 0.029 & & 0.028 \\
\hline Construction $1920-45$ & & -0.013 & & -0.013 \\
\hline Construction $1945-70$ & & -0.040 & & -0.040 \\
\hline Construction 1970-1985 & & -0.042 & & -0.042 \\
\hline Construction 1985-2000 & & $0.057^{*}$ & & $0.055^{*}$ \\
\hline Construction $>2000$ & & $0.107^{* * *}$ & & $0.104^{* * *}$ \\
\hline $\begin{array}{l}\text { Control variables (table D.10) and } \\
\text { socio-economic variables (table D.11) }\end{array}$ & $\checkmark$ & $\checkmark$ & $\checkmark$ & $\checkmark$ \\
\hline $\begin{array}{l}\text { Municipality dummies, month } \\
\text { dummies and year trend }\end{array}$ & $\checkmark$ & $\checkmark$ & $\checkmark$ & $\checkmark$ \\
\hline Observations & 13490 & 6112 & 13490 & 6112 \\
\hline Rho & -0.189 & 0.801 & -0.183 & 0.794 \\
\hline P-Value for Wald test & 0.000 & 0.000 & 0.000 & 0.000 \\
\hline
\end{tabular}

Exclusion restriction: share of electoral votes for green parties. Baseline is a rental advertisement for a dwelling disclosing a red rating in (1) and (2), or a $\mathrm{G}$ rating in (3) and (4). Robust standard errors in parentheses. Significance levels: ${ }^{*} p<0.10,{ }^{* *} p<0.05,{ }^{* * *} p<0.01$

Results across all specifications indicate that dwellings of high energy performance are associated with a rent premium, but that not all performance levels are necessarily valued higher than worst energy performance. We conclude that Hypothesis 1 is only partly verified in our setting: energy performance is valued in the Brussels rental market - but only at the very top of the distribution. This finding may have consequences on the disclosure incentives of landlords and ultimately hinder full information unraveling. Landlords will not find it valuable to disclose EPC ratings if they indicate intermediate quality potentially leading to low disclosure rates in this segment of the market.

More precisely, results of specification 1 indicate that dwellings disclosing a green rating gain a $6.9 \%$ rent premium with respect to otherwise similar dwellings with a red certificate, while the premium is of $1.9 \%$ for dwellings with an orange certificate. Both premiums are statistically significant at the $1 \%$ level. Similarly, results of specification 3 indicate that dwellings disclosing a $\mathrm{B}$ rating gain a $8.1 \%$ rent premium, compared to

municipalities: again, this is not the case, as the EPC regulation applies to all municipalities in Brussels. 
similar dwellings disclosing a G-rated certificate. The valuation decreases again with the performance level, C-rated and D-rated dwellings are associated with a $5.7 \%$ and $1.7 \%$ premium respectively. These premiums are statistically significant at the 1 to $5 \%$ level. No statistically significant premium is associated to lower-rated dwellings, except for rating $\mathrm{F}$ which is associated with a negative premium.

Specifications 2 and 4 additionally control for the year in which a dwellings' building was constructed. This variable is not available for all rental advertisements, thus the smaller sample size. We have constructed a factor variable taking different values for seven brackets (before 1900, 1900-1920, 1920-1945, 1945-1970, 1970-1985, 1985-2000, after 2000); dwellings built before the year 1900 represent the baseline. On the one hand, the coefficients on the construction year dummies capture parts of the value that is associated to energy performance. For example, recent buildings likely feature higher energy performance. On the other hand, a buildings' age may also capture other quality dimensions of a dwelling and is therefore controlled for.

Incorporating the age of the building in the estimation has an important effect on our results. The coefficients of EPC ratings decrease substantially while standard errors increase, to the extent that disclosing ratings that indicate intermediate energy performance (e.g. orange ratings in specification 2, and C- or D-rated EPCs in specification 4 ) is not found to be significantly different from disclosing lowest quality. When controlling for a building's age, only dwellings at the very top of the EPC rating distribution (green-rated and B-rated dwellings) benefit from a rent premium relative to low-rated dwellings, namely $3.7 \%$ and $5.2 \%$, respectively. Both premiums remain statistically significant at the $1 \%$ level.

As shown by the Wald test of independent equations, the null hypothesis of a zero correlation between the error terms of the selection and outcome equation $\left(H_{0}: \rho=0\right)$ can be rejected at the $1 \%$ significance level in all specifications. This suggests that sample selection is an issue in our dataset, justifying the use of the Heckman correction. Our preferred specifications 2 and 4 show that this correlation is positive $(\rho=0.8)$. When controlling for the age of a building, unobserved factors that are positively correlated with EPC disclosure in the selection equation tend to be associated with higher rental prices in the outcome equation. Dwellings that are expensive for some unobservable reasons are on average more likely to disclose an EPC. Finally, the exclusion restriction greenvote is estimated to have a positive and statistically significant effect on the probability of EPC disclosure in our model, as reported in the bottom panel of Table D.9 in the Appendix.

Results in the context of existing literature. Our results on the willingness to pay for energy performance align relatively well with the premiums found in earlier studies of other European countries. For example, Brounen and Kok (2011) identify an average price premium of $3.7 \%$ for dwellings with green EPC ratings relative to comparable dwellings with lower energy performance in the residential Dutch sales market. Analyzing the Irish residential rental market, Hyland et al. (2013) estimate that a dwelling disclosing an A rating earns an average rent premium of $1.8 \%$ compared to a D-rated dwelling. The premium is of $3.9 \%$ when B-rated dwellings are compared to D-rated counterparts.

Differences in the results might derive not only from the difference in the analyzed 
markets ${ }^{18}$ but also from differences in the datasets. Our analysis focuses on the value of energy performance for dwellings disclosing an EPC rating in the rental advertisement, which is the relevant margin to test assumption for the unraveling result, while Brounen and Kok (2011) cannot distinguish whether an EPC rating was actually disclosed to the potential buyer or not. Hyland et al. (2013) control for EPC disclosure but their reference group to model selection is the pool of all dwellings, whereas ours is the pool of dwellings that have obtained but hide an EPC. This is an important difference, as it allows us to make the disclosure decision depending on whether the housing unit was previously certified, which is important when exploring the disclosure incentives of homeowners.

Housing units as multidimensional goods. To test how multidimensionality affects the willingness to pay for energy performance in our setting, we analyze whether the rent premium associated with high disclosed energy performance varies with other dimensions or dwelling attributes. Therefore, we estimate a variation of the above Heckman selection model by adding interaction terms. To ease interpretation, we group EPC ratings into three categories: green $(\mathrm{B}-\mathrm{C})$, orange $(\mathrm{D}-\mathrm{E})$ and red $(\mathrm{F}-\mathrm{G})$, with the red category being the baseline. More precisely, in each specification presented in Table 4, the green EPC dummy is interacted with a different variable.

Our additional regression results indicate that some housing dimension indeed interact with the willingness to pay for energy performance: for example, green EPC ratings are rewarded relatively less when dwellings are renovated or new, and relatively more in municipalities where top (disclosed) energy performance is scarce as well as in richer neighborhoods.

Specification 1 shows that top energy performance is valued less on average in dwellings that are brand new or have recently been renovated compared to older housing units, although the coefficient is statistically significant only at the $10 \%$ level. Disclosing a green as opposed to a red EPC rating is positively valued in not recently renovated dwellings, yielding a $4.2 \%$ rent premium. This premium is much lower among dwellings which are brand new or have recently been renovated.

Specification 2 indicates that better energy performance is more highly rewarded where it is scarce. The dummy variable Red municipality takes the value 1 if the share of disclosed red EPCs out of all disclosed certificates in a given municipality exceeds the region-wide average share of red EPCs in a given year. We find that an additional rent premium of $2.4 \%$ is associated to high energy performance in municipalities with a relatively high share of disclosed, red-rated dwellings.

Finally, specification 3 assesses whether the willingness to pay for high as opposed to low energy performance varies with the purchasing power in a municipality. The dummy variable Top rent municipality takes the value 1 if the average rent per square meter in a given municipality in a certain year is higher than the region-wide average rent per square meter, and 0 otherwise. We find that disclosing a green as opposed to a red-rated dwelling is associated with a $2.2 \%$ rent premium in municipalities with an average rent lower than the regional average, while an additional $2.7 \%$ can be gained in a municipality where average rent is high. We interpret this as an indication that high

\footnotetext{
${ }^{18}$ For instance, Brounen and Kok (2011) and Hyland et al. (2013) study EPC effects pooling data from the entire country and Brounen and Kok (2011) look at sales only. Conversely, our study focuses on rentals and dwellings in an urban context.
} 
Table 4: The valuation of energy performance across dwelling types and locations

\begin{tabular}{|c|c|c|c|}
\hline & $(1)$ & $(2)$ & $(3)$ \\
\hline & \multicolumn{3}{|c|}{ Log(real rent/sqm) } \\
\hline \multirow[t]{2}{*}{ Green $=1$} & $0.042^{* * *}$ & $0.025^{* *}$ & $0.022^{*}$ \\
\hline & $(0.010)$ & $(0.011)$ & $(0.011)$ \\
\hline \multirow[t]{2}{*}{ New $/$ renovated $=1$} & $0.046^{* * *}$ & & \\
\hline & $(0.008)$ & & \\
\hline \multirow{2}{*}{ New $/$ renovated $=1 \times$ Green $=1$} & $-0.022^{*}$ & & \\
\hline & $(0.013)$ & & \\
\hline \multirow[t]{2}{*}{ Red municipality $=1$} & & -0.001 & \\
\hline & & $(0.011)$ & \\
\hline \multirow[t]{2}{*}{ Red municipality $=1 \times$ Green $=1$} & & $0.024^{* *}$ & \\
\hline & & $(0.011)$ & \\
\hline \multirow[t]{2}{*}{ Top rent municipality $=1$} & & & 0.019 \\
\hline & & & $(0.013)$ \\
\hline \multirow[t]{2}{*}{ Top rent municipality $=1 \times$ Green $=1$} & & & $0.027^{* *}$ \\
\hline & & & $(0.011)$ \\
\hline \multirow[t]{2}{*}{ Orange } & 0.010 & 0.010 & 0.010 \\
\hline & $(0.008)$ & $(0.008)$ & $(0.008)$ \\
\hline Year of construction dummies & $\checkmark$ & $\checkmark$ & $\checkmark$ \\
\hline Control and socio-economic variables & $\checkmark$ & $\checkmark$ & $\checkmark$ \\
\hline $\begin{array}{l}\text { Municipality dummies, month } \\
\text { dummies and year trend }\end{array}$ & $\checkmark$ & $\checkmark$ & $\checkmark$ \\
\hline Observations & 6112 & 6112 & 6112 \\
\hline Rho & 0.800 & 0.801 & 0.800 \\
\hline P-Value for Wald test & 0.000 & 0.000 & 0.000 \\
\hline
\end{tabular}

Exclusion restriction: share of electoral votes for green parties. Baseline is a rental advertisement for a dwelling disclosing a red EPC rating (i.e. F or G-rated). Robust standard errors in parentheses. Significance levels: ${ }^{*} p<0.10,{ }^{* *} p<0.05,{ }^{* * *} p<0.01$

energy performance is valued relatively more in rich neighborhoods compared to poorer ones (roughly twice as much).

\subsection{Discussion}

Our results indicate that tenants in the Brussels rental market are willing to pay a positive premium for better energy performance, but that the premium is restricted to high performance only. Intermediate energy performance is associated with relatively low rental premiums, which creates a weaker incentive for landlords to disclose this type of quality information. This, in turn, inhibits the full unraveling of information.

In Section 2, we have discussed potential explanations for such valuation patterns found in the literature. For example, tenants may not be willing to pay for energy performance because they are unable to interpret EPC information. Due to the complex nature of energy markets and energy consumption, tenants may have difficulties evaluating the monetary savings associated with different levels of energy performance and to understand the value of EPC ratings. More specifically, consumers may not be able to discern intermediate performance levels through other channels, when a certificate is missing.

Our data documents a mismatch between the costs and benefits associated with renting an apartment with high energy performance. This lends some support to the idea that, in Brussels, tenants face difficulties in translating better energy performance into estimated monetary savings. For example, living in a B-rated instead of a G-rated 
housing unit implies an average rent premium of $5.2 \%$, which amounts to a rent increase of 57 euro per month for an average Brussels-based dwelling. On the benefits side, living in a B-rated as opposed to a G-rated housing unit reduces energy consumption by at least $70 \%$, translating into a lower energy bill by approximately 75 to 150 euros per month. ${ }^{19}$ The value of better energy performance in the form of lower energy bills is not fully reflected in rents, which complicates the evaluation of monetary benefits. It also directly affects landlords' disclosure incentives

Another explanation for why tenants may not be willing to pay a premium for all levels of energy performance is the multidimensional character of housing. If tenants value other dwelling dimensions, such as living in a specific neighborhood or in a specific type of dwelling, they may attribute less importance to energy performance.

Our results show that some housing dimensions also affect the valuation of energy performance in the Brussels market. In particular, the willingness to pay for top energy performance is higher when dwellings are not renovated, where most of housing units are of worse thermal quality as well as in rich neighborhoods. The latter raises equity concerns, as a budget-constrained tenant may need to opt for a dwelling with lower energy performance to take advantage of lower rent that has to be paid immediately, while risking a higher energy bill in the future.

Limitations of methodology and data. Our dataset has many advantages which enable us to infer the willingness to pay for energy performance while accounting for the fact that a certificate has been obtained and disclosed. This is important when analyzing the disclosure incentives of landlords and testing the assumptions underlying the unraveling result directly. However, some caveats apply.

First, we use the EPC rating as a proxy for a dwelling's energy performance. Strictly speaking, the coefficient associated to the EPC rating in Table 3 (i.e. $\beta$ in model (1)) does not gives us the full value of energy performance but the marginal value of the certificate, conditional on controlling for other elements that contribute to a tenant's assessment of the energy performance of a housing unit (e.g. the year of construction). Tenants may infer energy performance by observing other attributes as well. In that sense, our interpretation of the valuation of energy performance may be a lower bound, as it only captures the marginal value of the EPC rating.

Second, our analysis accounts for the potential non-random selection associated with the disclosure decision. However, a remaining issue relates to the endogeneity between a specific EPC rating and unobserved dwelling characteristics that also affect rents. For example, dwellings with a green EPC may overall be of high quality, which implies high rent, but we may not observe all quality determinants. We address this additional endogeneity problem by explicitly controlling for indicators of dwelling quality (such as dwelling equipment and building features) and specific municipality-level indicators of location quality (e.g. quality of school offer, the public transport system).

Although some omitted variable bias might remain, we are confident that this bias remains small. Working with an almost exhaustive list of dwelling characteristics conveyed in rental ads, we are reproducing very precisely the information that a potential tenant can retrieve by screening the ad and which supposedly drives the advertised rent. This should relieve most of the potential problem of omitted variable bias. To control

\footnotetext{
${ }^{19}$ This back-of-the-envelope calculation requires several assumptions, e.g. on the energy source used for heating. Detailed calculations are reported in Appendix C.
} 
for any remaining endogeneity between EPC rating and rent, we perform a robustness check using an alternative dependent variable, ad duration.

\subsection{Robustness checks}

As a robustness check, we use different specifications of our baseline model, changing the way we control for the time of publication of the rental ad on the real estate website. Instead of controlling for the year when the rental ad was published in a continuous way, with a yearly trend, both specifications of Table D.12 in the Appendix include year dummies, thus controlling for time of publication in a more flexible way. Specification 1 includes month dummies in addition, while specification 2 includes quarter dummies.

The rent premiums identified through our main model (Table 3) are robust to these alternative model specifications, both in magnitude and in statistical significance. However, the share of green votes is no longer found to have a statistically significant impact in the selection equation: this might be due to year of publication dummies absorbing part of the variation related to greenvote.

Next, we estimate our model using an alternative dependent variable to control for the potential endogeneity between EPC rating and rent. To this end we exploit information on advertisement duration, measuring the number of days during which a rental advertisement was present on the Immoweb website. We estimate a Heckman selection model as explained in Section 4.1, with the difference that the dependent variable in the outcome equation (1) is replaced by ad duration.

The estimated coefficients associated with the main explanatory variables are reported in Table D.13 in the Appendix and confirm the results of our main specification. ${ }^{20}$ Dwellings that disclose a green or orange certificate stay on average for a shorter period of time on the market compared to similar dwellings disclosing a red EPC. The coefficients are statistically significant at the $5 \%$ level. These results confirm that, even when controlling for the endogeneity between EPC color category and rent, the residential housing market values energy performance conveyed through a disclosed EPC. Dwellings disclosing a better energy performance find a tenant faster than those disclosing lower performance.

From estimating the same model with disaggregated letter-based ratings (Specification 4), we find that dwellings disclosing a higher energy performance rating do not appear to stay for a statistically significant shorter duration on the website. However, the main take-home remains the same: had Hypothesis 1 been verified, we would have expected all relative improvements in energy performance with respect to the baseline to be reflected in a proportionally shorter time on the market. This is not the case once we zoom on disaggregated letter ratings, thus providing additional evidence for why information unraveling is not observed in this specific context.

\section{The informational value of certificates: testing Hypothesis 2}

In this section, we test whether another fundamental assumption necessary for the theoretical result of full information unraveling is verified in our context. Hypothesis

\footnotetext{
${ }^{20}$ In all specifications the exclusion restriction has a significant impact in the selection equation. Note that in none of the specifications, we can reject the null hypothesis that there is random selection in our sample, as the p-value of the Wald test indicates.
} 
2 requires that, whenever a landlord does not disclose a dwelling's EPC rating, prospective tenants rationally update downward their beliefs about its energy performance. Such behavior on the tenant side provides landlords with an incentive to disclose the dwelling's EPC rating, as long as the rent conditional on disclosing it is higher than the rent conditional on hiding it. A failure of Hypothesis 2 may explain the observed low disclosure rates. Therefore, we are interested in testing whether dwellings earn a rent premium by disclosing energy performance information instead of hiding it: we call this premium the informational value of EPCs.

\subsection{Empirical strategy}

To verify whether Hypothesis 2 holds in our sample, we estimate the informational value of EPCs merging the sample of compliers to that of non-compliers. We consider the following hedonic price model, where the binary variable $D i s c_{i}$ takes the value 1 (resp. 0) if an EPC rating is disclosed (resp. hidden) in the rental ad. All other control variables are as defined in the previous section:

$$
\log \left(p_{i}\right)=\alpha+\beta \text { Disc }_{i}+\mathbf{X}_{\mathbf{i}} \gamma+\mathbf{A}_{\mathbf{i}} \kappa+\mathbf{M}_{\mathbf{i}} \delta+\mathbf{Z}_{\mathbf{i}} \zeta+\epsilon_{i}
$$

We estimate this model in separate subsamples in order to isolate the informational value of disclosing an EPC rating, while keeping the energy performance level constant. In particular, we focus on the subsample of orange and red-rated housing units, where the disclosure rate is lower than $75 \%$ (see Table 1 ). ${ }^{21}$

Estimating this model by OLS we might run into an endogeneity problem, as the decision to disclose an EPC rating is likely correlated with unobserved dwelling characteristics that may also affect rent. To address this problem, we adopt an instrumental variable approach and estimate equation (3) by 2 -stage least squares (2SLS). ${ }^{22}$

We use the share of green voters in each municipality (greenvote) as an instrument for the endogenous variable of interest, EPC disclosure. For this to be a good instrument, it should have three characteristics: it should be correlated with EPC disclosure (instrument relevance), it should have no effects on rent other than through EPC disclosure (instrument exogeneity), and it should be as good as randomly assigned.

First, as explained in Section 4.1, greenvote can be interpreted as an exogenous determinant of EPC disclosure: while the share of green voters in a given municipality increases, landlords are pressured to disclose their EPC rating to a pool of environmentallyaware tenants. Second, we are confident that the share of green votes influences rents only via the channel of EPC disclosure, given that we control for variables which might affect both rents and EPC disclosure (e.g. average income per capita, public transport access, fixed municipality-level characteristics such as the presence of green spaces). Third, because we control for a number of socio-economic variables which may significantly impact voting behavior, we argue that this instrument is as good as randomly assigned.

We adjust our 2SLS estimation because our endogenous variable Disc $_{i}$ is binary. A binary endogenous variable is likely associated with a binary conditional expectation

\footnotetext{
${ }^{21}$ An alternative specification could estimate model (3) in samples that are split by letter-based EPC rating. However, this yields sample sizes that are too small for robust inference.

${ }^{22}$ An alternative strategy to estimate the informational value of EPCs accounting for the endogeneity might rely on matching.
} 
function in the first stage of a conventional 2SLS estimation. Following Angrist and Pischke (2008), we therefore estimate the first stage using a probit model which helps better approximate this nonlinear function. We set up the probit model as follows, where $\Phi(\cdot)$ is the standard normal cumulative distribution function:

$$
\operatorname{Pr}\left(\text { Disc }_{i}=1\right)=\Phi\left(\alpha+\text { ngreenvote }_{i}+\mathbf{X}_{\mathbf{i}} \psi+\mathbf{A}_{\mathbf{i}} \theta+\mathbf{M}_{\mathbf{i}} \xi+\mathbf{Z}_{\mathbf{i}} \mu+u_{i}\right)
$$

Based on our estimates from model (4), we calculate nonlinear fitted values, which we label DiscHat. It would be erroneous to follow the conventional approach of a 2SLS estimation and plugging these fitted values instead of Disc in the second stage of the 2SLS model, because the residuals from the estimation of the probit model might not be uncorrelated with fitted values and covariates.

Instead we follow Angrist and Pischke (2008) and estimate (3) by 2SLS using as instrumental variable the time-varying share of green voters per each municipality (greenvote). It enters stage 1 through the fitted values of the estimated probability disclosure (DiscHat) that were derived from the probit model. For this reason, we refer to probit model (4) as "stage 0" of the 2-stage least squares estimation.

The results from the estimation of stage 2 convey the informational value of EPCs, which we present in the next subsection. The results from the estimation of stage 0 (probit model (4)) and of stage 1 are reported in the Appendix. Table E.14 reports results from the estimation of stage 0 and shows that greenvote is a relevant factor in the estimation of EPC disclosure: a higher relative share of votes cast in favor of green parties is likely to positively and significantly affect disclosure of energy performance information. Table E.15 reports results from the estimation of stage 1 and indicates that the instrumental variable DiscHat is statistically significant in stage 1 .

We test for weak identification of the endogenous regressor, using a test proposed by Olea and Pflueger (2013), which is applicable to a setting with one endogenous variable and errors that are not conditionally homoskedastic. The 2SLS estimator is asymptotically unbiased under strong instruments, whereas this is not the case under weak instruments. The test calculates a proxy for 2SLS bias relative to an OLS benchmark, based on a scaled version of the nonrobust first-stage F-statistic, indicated as "modified F-statistic" in Table E.17 (Olea and Pflueger, 2013).

Table E.17 in the Appendix reports full results from the test. The null hypothesis of weak instruments can be rejected when the effective $\mathrm{F}$ is larger than the critical value. More precisely, the table reports $5 \%$ critical values for testing the null hypothesis that the bias exceeds the OLS benchmark by a certain magnitude (e.g. that it exceeds $5 \%$, $10 \%, 20 \%$ or $30 \%$ of the OLS benchmark). Our results show that we can reject the hypothesis of weak instruments in both specifications.

\subsection{Results}

With an instrumental variable approach, we test whether Hypothesis 2 is verified in the Brussels rental market: we assess whether consumers update downwards their beliefs regarding undisclosed energy performance information of housing units for rent. Table 5 presents results from the estimation of model (3), i.e. the second stage of 2SLS. The dependent variable is the natural logarithm of real rent per square meter. Standard errors are corrected for heteroskedasticity. Our model includes the same control variables presented in Section 4.1 and summarised in Table B.6, in order to account for features of housing units, for socio-economic characteristics of the municipality in which the unit 
for rent is located, and for characteristics of the rental advertisements. All specifications control for the year of construction of housing units.

Table 5: The informational value of energy performance certificates

\begin{tabular}{lcc}
\hline \hline & \multicolumn{2}{c}{ Dep. var.: $\log ($ real rent/sqm) } \\
& $(1)$ & $(2)$ \\
& Ads with orange EPC & Ads with red EPC \\
\hline Disclosed EPC & 0.086 & $-0.265^{* *}$ \\
& $(0.067)$ & $(0.130)$ \\
\hline Control variables and & $\checkmark$ & $\checkmark$ \\
socio-economic variables & & $\checkmark$ \\
Municipality dummies, month & $\checkmark$ & $\checkmark$ \\
dummies and year trend & & 0.294 \\
Year of construction dummies & $\checkmark$ & 1067 \\
\hline R2 & 0.603 & \\
Observations & 3021 & \\
\hline \hline
\end{tabular}

2SLS estimation (stage 2). Dependent variable: $\log$ (real rent/sqm). Robust standard in parentheses. Spec (1) ads with disclosed orange EPC vs ads with hidden orange EPC (2) ads with disclosed red EPC vs ads with hidden red EPC. Significance levels: ${ }^{*} p<0.10,{ }^{* *}$ $p<0.05,{ }^{* * *} p<0.01$

We are interested in comparing the "within" impact of EPC disclosure among dwellings within the same EPC rating category. This amounts to understanding whether ads disclosing an EPC get a rent premium relatively to ads hiding the same rating, while allowing us to abstract from the value of energy performance signals.

Each specification differs by the sample in which the estimation is carried out. In specification 1, we focus on the subsample of ads with orange EPCs (i.e. with D-E ratings), comparing ads which disclose or hide their EPC rating. In specification 2, we perform the same analysis in the subsample of ads with red EPCs (i.e. with F-G ratings). Due to small sample sizes the specifications could not be broken down by letter.

While full results are reported in Table E.16 in the Appendix, Table 5 focuses on the coefficient of interest, $\beta$, associated with the impact that EPC disclosure has on rent. This coefficient represents the informational value of certificates, that is, the value that tenants associate to disclosed as opposed to hidden EPC information when screening the rental market. According to the unraveling theorem, if consumers rationally update downwards their beliefs regarding a dwelling's energy performance in the absence of an EPC rating, we would find rent penalties associated with dwellings that hide this piece of information. Consequently, the informational value associated with a disclosed certificate should be positive and statistically significant, or, at most, insignificant for lowest quality levels, indicating indifference.

Results from specification 1 show that, among dwellings with an EPC rating signalling intermediate energy performance (i.e. orange EPCs), there is no evidence that this informational value is statistically significant: it appears that disclosing an EPC certificate does not lead to a rent premium relative to dwellings hiding energy performance information. Consumers do not appear to update downward their beliefs on energy performance in this case, as they do not penalize the lack of a credible signal.

Among dwellings with an EPC rating signaling low energy performance (i.e. red 
EPCs), the disclosure of an EPC certificate results in a statistically significant rent penalty $(-26.5 \%)$ relative to otherwise similar dwellings disclosing a comparable rating. This is counterintuitive in the framework of the unraveling result. Focusing on ads with the lowest possible energy performance in the market, we would expect at a maximum the rent difference between ads hiding or disclosing a red EPC to be non-statistically significant. This is not the case: consumers appear to even penalize rather than reward the disclosure of information, which is not consistent with the rational expectations assumption. ${ }^{23}$

Results in context of existing literature. To the best of our knowledge, this is the first study quantifying the informational value of energy performance certificates, which allows us to directly test the disclosure incentives of landlords in a setting of voluntary disclosure. Thanks to our novel dataset, which provides information on the energy performance of a dwelling both when EPCs are hidden and disclosed, we can assess an additional reason for the unraveling of information to break down in the present context.

Only few studies discuss the likelihood of disclosing EPC information by comparing the effects of policy changes implying a shift from voluntary to mandatory disclosure of EPCs. However, previous literature does not pin down the informational value of energy performance indicators.

Studying the policy shift from voluntary to mandatory EPC disclosure in Germany, Frondel et al. (2018) find that owners of dwellings with low energy performance tend to strategically withhold this information from ads, unless disclosure is mandatory. Following the policy change, prices for new compliers drop on average by over $11 \%$, and more so for dwellings with lower energy performance: this result is in line with our finding relative to the subgroup of ads with red EPCs, which are penalised for disclosing their rating. However, our advantage with respect to this paper lays in our ability to directly measure disclosure incentives, as we consider a context where disclosure is de facto voluntary and can estimate the informational value of certificates for a given performance level.

Analyzing the market in the region of Canberra, Australia, Fuerst and Warren-Myers (2018) show that dwellings with more sustainability features (e.g. energy-efficient heating systems, windows and insulation, presence of solar panels) are more likely to disclose their EPC rating. However, they cannot empirically test the assumptions underlying the unraveling theorem.

Finally, Olaussen et al. (2017) observe data on real estate transactions in Oslo, Norway, before and after the introduction of mandatory EPC disclosure. Assuming the dwellings maintain the same EPC rating throughout the 15-year time window of their dataset (which amounts to ruling out any renovation works), they find that energy efficiency ratings were valued even prior to mandatory disclosure. They interpret this as evidence that certificates do not convey any additional information, but this result should be interpreted with caution due to their implicit assumption of constant energy performance in time.

\footnotetext{
${ }^{23}$ Our finding that disclosing low energy performance ratings is penalized may be consistent with loss aversion, whereby consumers tend to prefer avoiding a loss as opposed to acquiring a gain of the same magnitude.
} 


\subsection{Discussion}

Findings reported in Table 5 show that Hypothesis 2 is not verified in the Brussels rental market: tenants do not update downwards their beliefs about undisclosed energy performance. Specifically, dwellings of intermediate energy performance are not valued differently whether the EPC rating is hidden or disclosed. On the other hand, dwellings of low energy performance are penalized through a lower rent when disclosing EPC information.

In Section 2 we have discussed potential explanations for why consumers may fail to update downwards their beliefs regarding undisclosed product quality. Because people rarely move between different dwellings, they may not learn easily what hidden energy performance information stands for. Without this learning process, it is hard for tenants to rationally update their beliefs about dwellings' energy performance in the absence of EPC ratings. They will consequently remain "insufficiently skeptical" about undisclosed information.

Further, as EPC disclosure is low in the Brussels rental market, potential tenants build their beliefs on average energy performance on a very limited and likely not representative subset of dwellings. Not observing the full distribution of EPC ratings, tenants might have unrealistic expectations about the average energy performance on the market. Tenants might be unaware of EPC regulation, thus paying little attention to EPC ratings and not fully understanding them or entirely disregarding them: the presence of unsophisticated, naïve tenants might contribute to lower information disclosure.

More specifically, results from the subset of ads with an orange EPC indicate that tenants do not associate a positive value to disclosure of certified information on intermediate energy performance. This might be connected to findings from Section 4, which indicate that tenants only positively valuate top energy performance signals. Instead, results from the subset of ads with a red EPC indicate that consumers penalize disclosure of dismal energy performance. This might be due the fact that consumers receive a disutility from the "bad news" brought by a low EPC rating, hence they prefer not to see hard information conveying it.

The fact that consumers do not assign lower values to housing units that hide quality information has a direct impact on landlords' disclosure incentives and may explain the failure of the unraveling result that we observe in the Brussels rental market. But in the present case, why then would landlords disclose a red rating, incurring in a rent penalty? Despite the lower prices associated with disclosing some energy performance levels, it may still be optimal for some landlords to reveal this piece of information. One can think of them as being either compliers that abide by the law which makes disclosure compulsory because of personal preferences ("full compliers"), or because they misestimate the risk for compliance checks. Some landlords may overestimate the risk of being fined for not complying with regulation mandating EPC disclosure: if this is the case, they might perceive the expected value of a fine as greater than the expected value of a rent penalty. These landlords will always disclose their certificate, regardless of the energy performance of the housing unit.

Limitations of the methodology and data. While our dataset has many advantages which enable us to assess the informational value of a disclosed EPC while abstracting from the value of energy performance (as measured by the EPC rating), some limitations should be noted. 
The subsample of rental advertisements with hidden EPC ratings is likely censored. We are able to retrieve whether ads hide an EPC rating only when they indicate a certificate ID. In this circumstance, we can match an advertised dwelling to data in the official EPC registry, and retrieve its actual EPC rating. However, there may be other rentals that hide EPC information from the ad without disclosing the certificate ID and which we cannot track.

Further, our analysis studies only a subset of the dwelling market in Brussels, focusing on dwellings that have been certified in the first place. This is a necessary step in our analysis of the unraveling result. Restricting our sample to dwellings that have obtained a certificate has two benefits. First, it allows us to study a situation where EPC disclosure is eventually costless (i.e. certificate costs are sunk). Second, it allows us to verify whether tenants exhibit rational expectations by updating downwards their beliefs about undisclosed energy performance. This amounts to testing whether there is a price difference between dwellings disclosing or hiding an EPC, keeping constant energy performance. This is what we call the informational value of certificates conditional on energy performance: nevertheless, results on the informational value of certificates should be interpreted as the average treatment effect on dwellings that have previously obtained an EPC.

\subsection{Robustness checks}

As a first robustness check, we estimate by OLS a hedonic pricing model similar to (1) in the subsample of ads with hidden EPC ratings. This allows us to test whether hidden energy performance ratings, which are not visible to tenants screening the rental market, are valued through rent premiums. If these ratings were estimated to yield a statistically significant rent premium, this would mean that perspective tenants can entirely deduce EPC information from other observable features of housing units (e.g. presence of double glazing), which would undermine our results.

Table E.18 in the Appendix reports results from the estimation of the above-described model. Specification 1 shows that hidden EPC ratings are not associated with a statistically significant rental premium relative to counterparts with red EPC ratings. Specification 2 confirms this by considering letter-based EPC ratings rather than aggregate color ratings. This indicates that tenants cannot perfectly infer energy performance of a dwelling when not observing its actual rating.

As a second robustness check, we test whether information disclosure impacts advertisement duration on the website. If Hypothesis 2 was verified and tenants assigned a lower value to undisclosed quality, we would expect this to translate into higher ad duration when EPC ratings are hidden. If tenants suspect dwellings hiding an EPC rating to be of lower quality, these dwellings should take a longer time to rent out and their ads should remain longer on the website, as tenants eschew non certified dwellings.

This is tested by estimating by 2SLS a model similar to (3), with the difference that the dependent variable is replaced with ad duration (measured in days). We follow the same instrumental variable approach described above: the endogenous binary variable indicating EPC disclosure is instrumented with the continuous variable greenvote, by estimating a probit model of EPC disclosure prior to the 2SLS. Results from the estimation of stage 2 are reported in Table E.19 in the Appendix: for dwellings with orange or red EPCs, ad duration is unaffected by disclosure. This provides additional evidence 
that tenants do not update downward their expectations about undisclosed EPCs. ${ }^{24}$

\section{Conclusions and policy recommendations}

Information-based policies are widely implemented to relieve information asymmetries. In the housing sector, policies that promote the use of energy performance certificates (EPCs) are widespread. However, recent evidence of low EPC disclosure rates in the residential rental market contradicts longstanding unraveling theories, according to which all landlords should disclose full information unless it is costly to do so. Our data shows that even when a certificate has been obtained, landlords do not always publish energy performance information.

In this paper, we derive testable hypotheses to explore disclosure incentives of landlords and understand why information unraveling may fail when it comes to disclosing energy performance information. This is crucial to understand reasons for low disclosure rates and has not been analyzed in previous literature due to data limitations. We test these hypotheses using a new dataset of rental advertisements from the Brussels rental market. The dataset and policy context provide and ideal framework to study landlords' disclosure decisions because it encompasses two of the key features of the unraveling result. First, disclosure of quality information is de facto voluntary in the period we analyze. Second, information disclosure can be seen as costless for those landlords who have obtained an EPC prior to advertising their dwelling on the rental website we obtain data from.

Our analysis suggests that two major assumptions of the theoretical unraveling result are not met in this context. First, tenants value energy performance and are willing to pay a rent premium only if it indicates top quality. As a consequence, landlords will not find it valuable to disclose EPC ratings that indicate quality levels that are not top of the class. Second, tenants do not rationally update downward their beliefs when facing housing units that do not disclose energy performance. This would make it worthwhile for a landlord to disclose quality information when it is above the level that tenants associate to unknown quality. Rather, we find that landlords gain a premium by hiding information that indicates low energy performance and do not gain anything by disclosing information at an intermediate quality level. Ultimately, the failure of these two assumptions directly affects the disclosure incentives of landlords and may explain the observed low disclosure rates of EPCs in this market.

Incomplete disclosure of energy performance information may have important consequences. EPC mechanisms will be less effective in relieving asymmetric information between tenants and landlords. In turn, this may raise distributional concerns, particularly in the rental market where energy performance is relatively low compared to owner-occupied housing, ${ }^{25}$ and energy bills can constitute a substantial share of disposable income. ${ }^{26}$ Low disclosure rates also have environmental consequences as the

\footnotetext{
${ }^{24}$ Results from the estimation of probit model (4) and stage 1 of the 2SLS are comparable to what reported in Tables E.14 and E.15, hence they are not reported for brevity. The null hypothesis of weak instruments can be rejected.

${ }^{25}$ OECD/IEA (2007) show that rented dwellings in the Netherlands are $42 \%$ less likely to have roof insulation compared to owner-occupied dwellings. Insulation of walls is $44 \%$, floors $46 \%$ and glazing $31 \%$ less likely. In the US context, Gillingham et al. (2012) show that rented dwellings where the resident pays for heating are $9 \%$ less likely to be insulated in the exterior walls.

${ }^{26}$ For example, in the Belgian rental market, $35 \%$ of all tenants spend more than $40 \%$ of disposable
} 
building sector accounts for $36 \%$ of $\mathrm{CO}_{2}$ emissions in the European Union (European Commission, 2017), energy performance certification is a fundamental tool for climate change mitigation in this sector of the economy.

Reforming EPC mechanisms to increase disclosure is therefore crucial. Enforcing compliance of mandatory disclosure rules may increase EPC disclosure. However, enforcement is costly, particularly when it requires monitoring numerous private landlords. Making professional agents (e.g. platforms for housing advertisements and real estate agencies) liable for respecting mandatory disclosure rules can reduce enforcement costs.

Besides enforcement, governments may grasp low-hanging fruits and increase disclosure rates in relatively low-cost ways by reforming voluntary disclosure regimes as follows. First, simplifying information that is included in EPCs can help tenants better understand them and facilitate the valuation of energy performance. Seemingly abstract EPC ratings can be made more relevant for tenants by connecting them to the concrete advantages of higher efficiency. For example, EPC templates could display estimated financial savings that one can reap by opting for an energy efficient dwelling, in which energy consumption and thus bills will be lower.

Second, publicly advertising the full distribution of energy performance in a city or neighborhood may enable tenants to better assess the relative value of a specific dwelling's energy performance. In the Brussels case, were tenants aware that the average energy performance of buildings is relatively low (between D and E), rent premiums may not apply exclusively to highly energy efficient dwellings. In this sense, displaying the energy performance distribution at a neighborhood or city level in the certificates, in awareness campaigns and advertisement platforms may make relative thermal quality more salient and well-known.

Finally, awareness-raising campaigns that inform tenants and landlords about the mandatory nature of the EPC regulation as well as about the gains from improved performance may enable fully informed rental choices. Better informed tenants are likely to increasingly opt for more energy efficient housing units, rewarding landlords' investment in energy performance with positive rental premiums. ${ }^{27}$ This should increase disclosure rates of energy performance information and would enable to fully embrace the benefits that come with an information-based policy, such as the EPC regulation. Finally, in the longer term, the reward for energy efficiency investment is bound to improve the aggregate thermal quality of the rental pool, driving down the energy consumption of the residential sector with the associated benefits for consumers' energy bills and the environment.

income on housing, whereas less than $5 \%$ of home owners do so. Note that tenants currently make up for $40 \%$ of all rental households in Brussels (OECD, 2015).

${ }^{27}$ Financial constraints of low-income households and a tight housing market will affect choices and may reduce the effectiveness of the policy. These features of the housing market would need to be taken into consideration as well. 


\section{Bibliography}

Abadie, A., Athey, S., Imbens, G. W., and Wooldridge, J. (2017). When should you adjust standard errors for clustering? Technical report, National Bureau of Economic Research.

Akerlof, G. A. (1970). The Market for "Lemons": Quality Uncertainty and the Market Mechanism. The Quarterly Journal of Economics, 84:488-500.

Angrist, J. D. and Pischke, J.-S. (2008). Mostly harmless econometrics: An empiricist's companion. Princeton University Press.

Bian, X. and Fabra, N. (2018). Incentives for information provision: A study of energy effciency in the spanish rental market. Unpublished Manuscript.

Brounen, D. and Kok, N. (2011). On the economics of energy labels in the housing market. Journal of Environmental Economics and Management, 62(2):166-179.

Dessouroux, C., Bensliman, R., Bernard, N., De Laet, S., Demonty, F., Marissal, P., and Surkyn, J. (2016). Housing in Brussels: diagnosis and challenges. BSI synopsis. Brussels Studies.

Dranove, D. and Jin, G. Z. (2010). Quality Disclosure and Certification: Theory and Practice. Journal of Economic Literature, 48(4):935-963.

Eichholtz, P., Kok, N., and Quigley, J. M. (2010). Doing Well by Doing Good? Green Office Buildings. American Economic Review, 100:2492-2509.

European Commission (2015). Energy Performance of Buildings Directive (EPBD) Compliance Study. Publications Office of the European Union.

European Commission (2017). Energy efficiency - Buildings. https://ec.europa.eu/ energy/en/topics/energy-efficiency/buildings. Accessed: 4/02/2017.

Fishman, M. J. and Hagerty, K. M. (2003). Mandatory Versus Voluntary Disclosure in Markets with Informed and Uninformed Customers. Journal of Law, Economics, and Organization, 19(1):45-63.

Forsythe, R., Isaac, R. M., and Palfrey, T. R. (1989). Theories and tests of "blind bidding" in sealed-bid auctions. RAND Journal of Economics, 20(2):214-238.

Frondel, M., Gerster, A., and Vance, C. (2018). The Power of Mandatory Quality Disclosure: Evidence from the German Housing Market. http://dx.doi.org/10. $2139 /$ ssrn. 2796532.

Fuerst, F. and Warren-Myers, G. (2018). Does voluntary disclosure create a green lemon problem? Energy-efficiency ratings and house prices. Energy Economics, 74:1-12.

Gillingham, K., Harding, M., and Rapson, D. (2012). Split Incentives in Household Energy Consumption. The Energy Journal, 33(2):37-62.

Gouvernement de la Région de Bruxelles-Capitale (2011). Arrêté du Gouvernement de la Région de Bruxelles-Capitale relatif au certificat PEB établi par un certificateur pour les habitations individuelles. Moniteur Belge. 
Grossman, S. J. (1981). The Informational Role of Warranties and Private Disclosure about Product Quality. The Journal of Law \& Economics, 24(3):461-483.

Harbaugh, R. and To, T. (2005). False Modesty: When Disclosing Good News Looks Bad. Working Papers 2005-05, Indiana University, Kelley School of Business, Department of Business Economics and Public Policy.

Hirshleifer, D. and Teoh, S. H. (2003). Limited attention, information disclosure, and financial reporting. Journal of Accounting and Economics, 36(1-3 SPEC. ISS.):337386.

Hyland, M., Lyons, R. C., and Lyons, S. (2013). The value of domestic building energy efficiency - evidence from Ireland. Energy Economics, 40:943-952.

Institut Bruxellois pour la Gestion de l'Environnement (2013). Le résultat du certificat peb pour le résidentiel. Infos Fiches-Énergie.

Jin, G. Z., Luca, M., and Martin, D. (2015). Is no news (perceived as) bad news? an experimental investigation of information disclosure. Technical report, National Bureau of Economic Research.

Jovanovic, B. (1982). Truthful Disclosure of Information. The Bell Journal of Economics, 13(1):36-44.

Kahn, M. E. and Kok, N. (2014). The capitalization of green labels in the california housing market. Regional Science and Urban Economics, 47:25-34.

Li, S., Peitz, M., and Zhao, X. (2016). Information disclosure and consumer awareness. Journal of Economic Behavior and Organization, 128:209-230.

Milgrom, P. and Roberts, J. (1986). Price and advertising signals of product quality. Journal of political economy, 94(4):796-821.

Milgrom, P. R. (1981). Good News and Bad News: Representation Theorems and Applications. The Bell Journal of Economics, 12(2):380-391.

OECD (2014). Greening Household Behaviour: Overview from the 2011 Survey - Revised edition. OECD Publishing, Paris, France.

OECD (2015). OECD Economic Surveys: Belgium 2015. OECD Publishing, Paris, France.

OECD/IEA (2007). Mind the Gap - Quantifying Principal-Agent Problems in Energy Efficiency. OECD Publishing, Paris, France.

Olaussen, J. O., Oust, A., and Solstad, J. T. (2017). Energy performance certificates Informing the informed or the indifferent? Energy Policy, 111:246-254.

Olea, J. L. M. and Pflueger, C. (2013). A robust test for weak instruments. Journal of Business 8 Economic Statistics, 31(3):358-369.

Wahlström, M. H. (2016). Doing good but not that well? A dilemma for energy conserving homeowners. Energy Economics. 
Walls, M., Gerarden, T., Palmer, K., and Bak, X. F. (2017). Is energy efficiency capitalized into home prices? Evidence from three U.S. cities. Journal of Environmental Economics and Management, 82:104-124.

Wooldridge, J. M. (2010). Econometric Analysis of Cross Section and Panel Data. MIT Press. 
Appendix A. EPCs in the region of Brussels

Figure A.2: Example of an EPC issued in Brussels

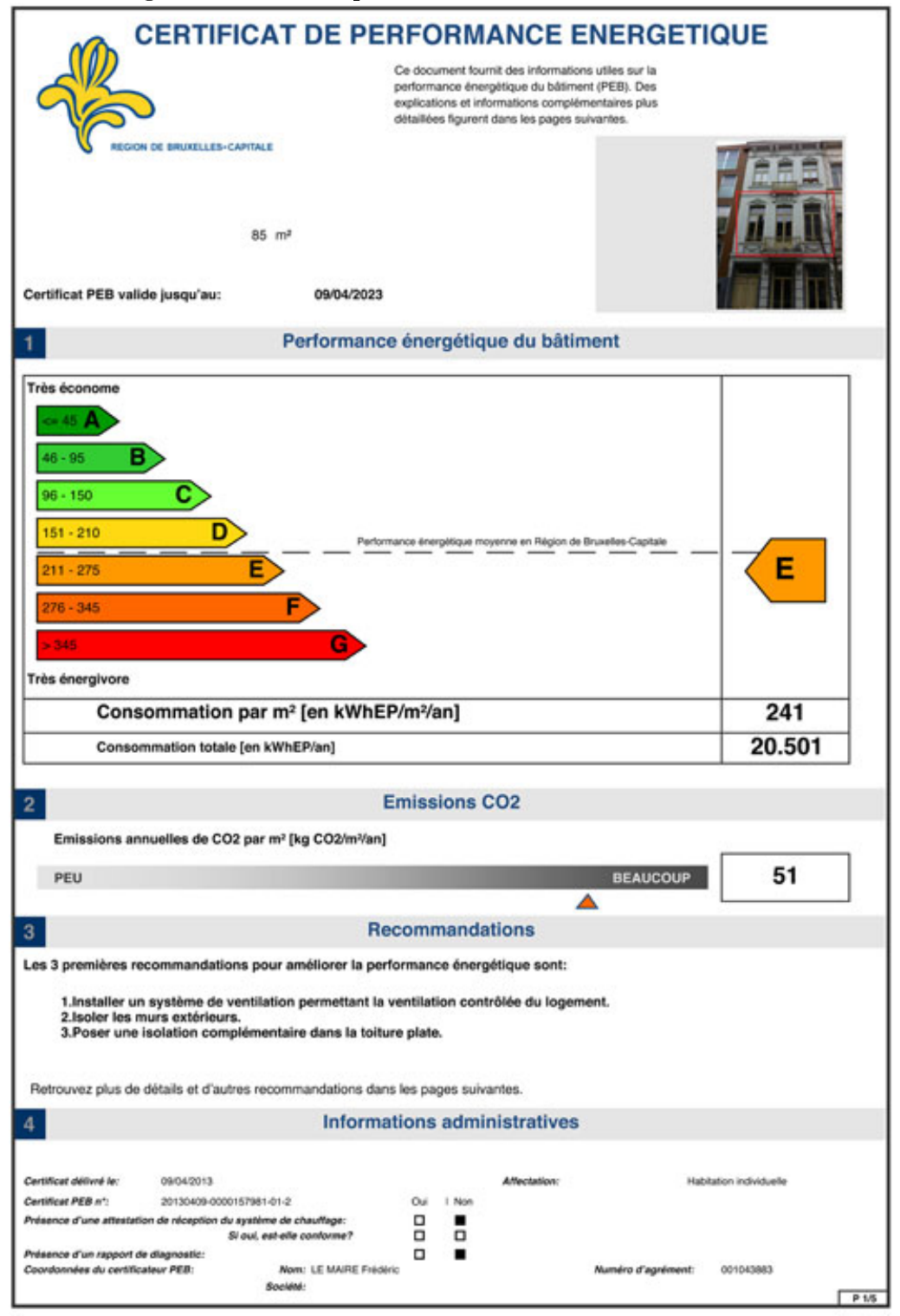


Figure A.3 shows that the introduction of mandatory disclosure policy in November 2011 lead to an increase in EPC disclosure, but that overall disclosure is far from being complete.

Figure A.3: EPC disclosure over time $(N=200,290)$

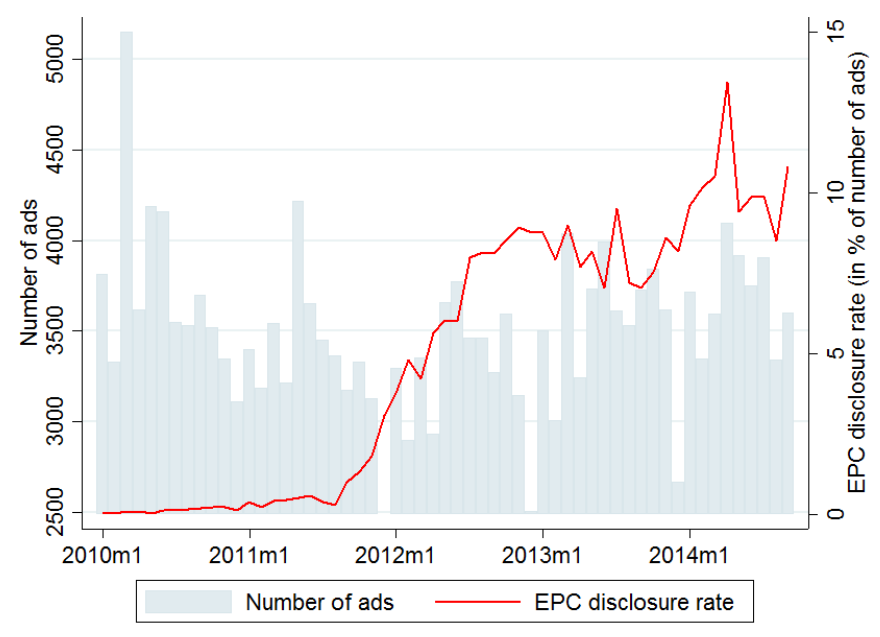

The bar graph reports the number of rental advertisements published every month on the Immoweb website between January 2010 and September 2014. The red line represents the percentage of rental ads disclosing an EPC rating relative to the total number of ads published in a given month. The November 2011 policy change was followed by a steep increase in the EPC disclosure rate, which then met a plateau starting from early 2013, with few peaks and troughs. In fact, of all rental ads published on the Immoweb website after November 2011, only 8\% disclose their EPC rating (9885 ads). Compliance with regulation has been disappointingly low. 


\section{Appendix B. Variable description}

Table B.6: Main variables by observation

\begin{tabular}{|c|c|}
\hline Variable name & Description \\
\hline & Energy performance certification ratings \\
\hline Green EPC & $\begin{array}{l}\text { Dummy taking the value of } 1 \text { if the ad has an EPC rating A, B or C; a value } \\
\text { of } 0 \text { if it has another EPC rating. }\end{array}$ \\
\hline Orange EPC & $\begin{array}{l}\text { Dummy taking the value of } 1 \text { if the ad has an EPC rating } D \text { or E; a value } \\
\text { of } 0 \text { if it has another EPC rating. }\end{array}$ \\
\hline Red EPC & $\begin{array}{l}\text { Dummy taking the value of } 1 \text { if the ad has an EPC rating } \mathrm{F} \text { or } \mathrm{G} \text {; a value } \\
\text { of } 0 \text { if it has another EPC rating. }\end{array}$ \\
\hline EPC rating & Factor variable indicating the specific A to G rating of a dwelling. \\
\hline & General dwelling features \\
\hline $\log ($ surface $)$ & Natural logarithm of dwelling's surface. \\
\hline $\mathrm{Nb}$ bedrooms & Number of bedrooms of the dwelling. \\
\hline $\mathrm{Nb}$ bathrooms & Number of bathrooms of the dwelling. \\
\hline Dwelling type & Dummy taking the value of 1 if the dwelling is a house / 0 if an apartment. \\
\hline $\begin{array}{l}\text { Year of con- } \\
\text { struction }\end{array}$ & Continuous variable indicating the year in which the dwelling has been built. \\
\hline
\end{tabular}

Access to open Dummy taking the value of 1 if the dwelling has a garden, terrace or balcony. space

Garage/parking Dummy taking the value of 1 if use of a garage or a parking spot are included in the rent.

Garage/parking Dummy taking the value of 1 if use of a garage or a parking spot are available extra upon payment of an extra fee.

Lift

Dummy taking the value of 1 if the dwelling has a lift.

Fully/partly fur- Dummy taking the value of 1 if the dwelling is fully or partly furnished.

nished

Luxury

Dummy taking the value of 1 if the dwelling has a private sauna, jacuzzi or pool.

Brand Dummy taking the value of 1 if the dwelling is brand new or renovated.

new/renovated

White goods

Dummy taking the value of 1 if a dish-washer, washing machine and/or dryer are included in the rent.

\section{Contract features}

Short-term con- Dummy taking the value of 1 if short-term rental contracts are possible.

tract

Real estate agency Dummy taking the value of 1 if the ad has been published by a real estate agency (as opposed to an individual).

\section{Features of the ad}

Multilingual ad Dummy taking the value of 1 if the dwelling's ad has a detailed description in more than 1 language (French, English and Dutch).

Ad length Number of words of the detailed dwelling description in the advertisement. 
Table B.7: Socio-economic variables by municipality

\begin{tabular}{|c|c|c|}
\hline Variable name & Description & Availability \\
\hline \multirow[b]{2}{*}{ EU-15/OECD } & Nationalities & \multirow[b]{2}{*}{ yearly* } \\
\hline & $\begin{array}{l}\text { Share of population from old EU member states and from } \\
\text { OECD member countries (except: Turkey, and Latin } \\
\text { America) }\end{array}$ & \\
\hline EU-New/Turkey & $\begin{array}{l}\text { Share of population from new EU member states and } \\
\text { Turkey }\end{array}$ & yearly* \\
\hline Other & $\begin{array}{l}\text { Share of population from Northern Africa and Sub- } \\
\text { Saharan Africa }\end{array}$ & yearly* \\
\hline \multicolumn{3}{|c|}{$\begin{array}{ll}\text { School capacity } \\
\end{array}$} \\
\hline Nursery & $\begin{array}{l}\text { Capacity of nurseries measured as the number of places } \\
\text { at nurseries by children in the municipality }\end{array}$ & yearly $^{* *}$ \\
\hline Primary school & $\begin{array}{l}\text { Capacity of primary school measured as the number of } \\
\text { pupils at a primary school compared to the total number } \\
\text { of children in the municipality }\end{array}$ & yearly \\
\hline Kindergarten & $\begin{array}{l}\text { Capacity of kindergarten measured as the number of pu- } \\
\text { pils at a kindergarten compared to the total number of } \\
\text { children in the municipality }\end{array}$ & yearly \\
\hline \multicolumn{3}{|c|}{ Workforce and income } \\
\hline Revenue & Average income per capita (in Euro) & yearly $^{* * *}$ \\
\hline Unemployment & $\begin{array}{l}\text { Share of unemployed job seekers measured as the total } \\
\text { number of unemployed job seekers compared to the total } \\
\text { number of } 18-64 \text { year old inhabitants }\end{array}$ & yearly* \\
\hline \multicolumn{3}{|c|}{$\begin{array}{l}\text { Municipality structure } \\
\end{array}$} \\
\hline Density & $\begin{array}{l}\text { Population density measured as total population compa- } \\
\text { red to the municipality's total surface }\end{array}$ & yearly* \\
\hline Office & $\begin{array}{l}\text { Office density measured as total floor space attributed to } \\
\text { offices compared to the municipality's total surface }\end{array}$ & yearly \\
\hline Social housing & $\begin{array}{l}\text { Share of social housing measured as the total number } \\
\text { of social housing } \times 100 \text { compared to number of private } \\
\text { households }\end{array}$ & yearly \\
\hline \multicolumn{3}{|c|}{$\begin{array}{ll}\text { Public transport } \\
\end{array}$} \\
\hline Public transport & $\begin{array}{l}\text { Share of population living close to a bus station }(200 \mathrm{~m}) \text {, } \\
\text { to a tram station }(400 \mathrm{~m}) \text { or to a metro station }(500 \mathrm{~m})\end{array}$ & $2012,2015^{* * * *}$ \\
\hline
\end{tabular}

${ }^{*}$ Extrapolation for year 2014; ${ }^{* *}$ Interpolation for years 2009 and 2012; ${ }^{* * *}$ Extrapolation for years 2013 and $2014 ;^{* * * *}$ Interpolation for remaining years. 


\section{Appendix C. The value of EPCs in context}

Estimating the rent premium associated to dwellings located in the region of Brussels disclosing an EPC shows that energy efficient, B-rated dwellings can earn on average $5.2 \%$ more rent than otherwise comparable but energy inefficient, G-rated ones. This effect is statistically significant. The present section performs simple back-of-the-envelope calculations to compare the cost and benefits from living in a B-rated as opposed to a G-rated housing unit, by contrasting the estimated rent premium to estimated energy savings for an average dwelling.

Costs. In our sample of compliers, the average dwelling with a G-rated energy performance certificate achieves a monthly rent of EUR 1,094 and measures 96 square meters. ${ }^{28}$ Our results on the valuation of energy performance suggest that, if the landlord of this average dwelling invested in energy efficiency measures to obtain at least a B rating, rent would increase by EU 57 on average (5.2\% of EUR 1,094). This monthly rent premium translates into a yearly additional gain of EUR 683, which represents more than $60 \%$ of the the average monthly rent.

Benefits. Assuming no behavioral changes, upgrading an apartment's energy performance to bring its EPC rating from the bottom to the top rating will translate into lower energy consumption and a lower energy bill for the tenant. Referring to Brussels EPC standards, a dwelling receives a $G$ rating if its estimated primary energy consumption exceeds $345 \mathrm{kWh} / \mathrm{sqm} /$ year. An EPC rating of B instead is associated with a primary energy consumption of up to $95 \mathrm{kWh} / \mathrm{sqm} /$ year. ${ }^{29}$ A tenant living in a dwelling that were to undergo an energy efficiency overhaul upgrading its EPC rating from $\mathrm{G}$ to $\mathrm{B}$, could reduce energy consumption by at least $72 \%$. This represents the most conservative estimate of energy savings. ${ }^{30}$ The gain associated with "going green" might be much higher.

A tenant living in an average-sized dwelling with a G-rated EPC consumes at least $2,768 \mathrm{kWh}$ of primary energy per month. So, "going green" by transitioning from a G to a $\mathrm{B}$ rating corresponds to a reduction in energy consumption of at least 2,008 $\mathrm{kWh}$ (72\%) per month.

Translating the reduction in energy consumption into a monetary gain for the tenant requires detailed knowledge about both the energy source used for heating and the energy supplier the tenant has signed up for. While we do not have precise information on both variables in our sample, we are able to provide an upper and lower bound of the monetary gain, assuming that households either use only gas or only electricity as heating source and that either the cheapest or the most expensive contract is chosen. Using the price simulator of the Brussels' energy regulator, ${ }^{31}$ we can calculate expected gains from energy efficiency upgrades. ${ }^{32}$

\footnotetext{
${ }^{28}$ As in the Results section, we report figures in real terms (base: January 2010).

${ }^{29}$ See consumption brackets associated with rating $G$ and B in Figure A.2.

${ }^{30}$ As displayed in Figure A.2, $72 \%$ corresponds to the difference in primary energy consumption between the best performing G-rated dwelling (lower bound of the $\mathrm{G}$ rating) and the least performing B-rated dwelling (upper bound of the B rating).

${ }^{31}$ Source: www . brusim.be.

${ }^{32}$ IBGE assumes that conversion from primary energy to electricity has an efficiency rate of $40 \%(2.5$ $\mathrm{kWh}$ of primary energy are needed to generate and supply $1 \mathrm{kWh}$ of electricity). The efficiency rate for gas is assumed to be $100 \%$ (IBGE, 2013).
} 
For a tenant living in an average-sized red apartment, "going green" would result in an energy bill reduction of 75 to 150 EUR per month. ${ }^{33}$

Costs and benefits. Comparing the costs and benefits accruing to tenants when a dwelling is upgraded from a low to a high energy performance suggests that the energy savings gains (EUR 75 - 150 per month) are higher than the rent premiums associated with dwellings complying with EPC disclosure regulation (EUR 57 per month).

This signals that the value of energy savings, which translates into lower energy bills, is not fully reflected in rent premiums. Non-monetary benefits of better thermal quality of dwellings (e.g. higher comfort) also seem to go unrewarded.

\footnotetext{
${ }^{33}$ These estimates include costs for gas or electricity, network and distribution, a VAT of $21 \%$ and other contributions as of April 2018 but expressed in 2010 prices. 75 EUR is the monthly expected gain for a home heated exclusively with gas and via the cheapest gas supplier. Conversely, 150 EUR is the monthly expected gain for a dwelling featuring electric heating and supplied by the most expensive electricity retailer.
} 


\section{Appendix D. Additional results and robustness checks: Section 4}

Table D.8 indicates that the share of green votes is a relevant driver of EPC disclosure. It summarizes results from estimating selection equation (2). Specifications 1 and 2, model the probability of disclosing an EPC with a linear probability model that is estimated by OLS, whereas specifications 3 and 4 use a probit model that is estimated by maximum likelihood. Specifications 2 and 4, control for a dwelling's year of construction. The positive and statistically significant coefficient of greenvote in all specifications indicates that landlord's are more likely to disclose an EPC, the higher the share of votes in favor of green parties in the municipality.

Table D.8: The determinants of EPC disclosure

\begin{tabular}{|c|c|c|c|c|}
\hline & $\begin{array}{c}(1) \\
\text { LPM }\end{array}$ & $\begin{array}{c}(2) \\
\text { Probit }\end{array}$ & $\begin{array}{c}(3) \\
\text { LPM }\end{array}$ & $\begin{array}{c}(4) \\
\text { Probit }\end{array}$ \\
\hline & \multicolumn{4}{|c|}{ EPC disclosure } \\
\hline Greenvote & $\begin{array}{c}0.863^{* * *} \\
(0.323)\end{array}$ & $\begin{array}{c}3.493^{* * *} \\
(1.292)\end{array}$ & $\begin{array}{c}0.893^{* * *} \\
(0.323)\end{array}$ & $\begin{array}{c}3.603^{* * *} \\
(1.290)\end{array}$ \\
\hline Green EPC & $\begin{array}{c}0.126^{\text {*** }} \\
(0.019)\end{array}$ & $\begin{array}{c}0.445^{* * *} \\
(0.067)\end{array}$ & & \\
\hline Orange EPC & $\begin{array}{c}0.054^{* * *} \\
(0.017)\end{array}$ & $\begin{array}{c}0.171^{* * *} \\
(0.055)\end{array}$ & & \\
\hline B & & & $\begin{array}{c}0.213^{* * *} \\
(0.029)\end{array}$ & $\begin{array}{c}0.781^{* * *} \\
(0.122)\end{array}$ \\
\hline $\mathrm{C}$ & & & $\begin{array}{c}0.118^{* * *} \\
(0.023)\end{array}$ & $\begin{array}{c}0.404^{* * *} \\
(0.081)\end{array}$ \\
\hline $\mathrm{D}$ & & & $\begin{array}{c}0.078^{* * *} \\
(0.023)\end{array}$ & $\begin{array}{c}0.251^{* * *} \\
(0.076)\end{array}$ \\
\hline $\mathrm{E}$ & & & $\begin{array}{c}0.033 \\
(0.023)\end{array}$ & $\begin{array}{c}0.079 \\
(0.076)\end{array}$ \\
\hline ( & & & $\begin{array}{c}0.004 \\
(0.029) \\
\end{array}$ & $\begin{array}{l}-0.008 \\
(0.090) \\
\end{array}$ \\
\hline Year of construction dummies & $\checkmark$ & $\checkmark$ & $\checkmark$ & $\checkmark$ \\
\hline Control and socio-economic variables & $\checkmark$ & $\checkmark$ & $\checkmark$ & $\checkmark$ \\
\hline $\begin{array}{l}\text { Municipality dummies, month } \\
\text { dummies and year trend }\end{array}$ & $\checkmark$ & $\checkmark$ & $\checkmark$ & $\checkmark$ \\
\hline Observations & 6112 & 6112 & 6112 & 6112 \\
\hline $\mathrm{R} 2$ & 0.234 & & 0.237 & \\
\hline Pseudo R2 & & 0.223 & & 0.227 \\
\hline
\end{tabular}

Baseline is a rental advertisement for a dwelling disclosing a red rating in (1) and (2), or a $\mathrm{G}$ rating in (3) and (4). Robust standard errors in parentheses. Significance levels: ${ }^{*} p<0.10$, ** $p<0.05,{ }^{* * *} p<0.01$ 
Table D.9: The valuation of energy performance (outcome and selection)

\begin{tabular}{|c|c|c|c|c|}
\hline & (1) & $(2)$ & $(3)$ & $(4)$ \\
\hline Outcome equation & & Log(real & ent/sqm) & \\
\hline Green EPC & $\begin{array}{c}0.069^{* * *} \\
(0.005)\end{array}$ & $\begin{array}{c}0.037^{* * *} \\
(0.010)\end{array}$ & & \\
\hline Orange EPC & $\begin{array}{c}0.019^{* * *} \\
(0.005)\end{array}$ & $\begin{array}{c}0.010 \\
(0.008)\end{array}$ & & \\
\hline B & & & $\begin{array}{c}0.081^{* * *} \\
(0.010)\end{array}$ & $\begin{array}{c}0.052^{* * *} \\
(0.016)\end{array}$ \\
\hline $\mathrm{C}$ & & & $\begin{array}{c}0.057^{* * *} \\
(0.007)\end{array}$ & $\begin{array}{c}0.020 \\
(0.012)\end{array}$ \\
\hline $\mathrm{D}$ & & & $\begin{array}{c}0.017^{* *} \\
(0.006)\end{array}$ & $\begin{array}{c}0.001 \\
(0.012)\end{array}$ \\
\hline $\mathrm{E}$ & & & $\begin{array}{c}0.003 \\
(0.007)\end{array}$ & $\begin{array}{c}-0.006 \\
(0.012)\end{array}$ \\
\hline $\mathrm{F}$ & & & $\begin{array}{c}-0.018^{* *} \\
(0.007)\end{array}$ & $\begin{array}{l}-0.026^{*} \\
(0.014)\end{array}$ \\
\hline Selection equation & & $\mathrm{EPC} \mathrm{d}$ & closure & \\
\hline greenvote & $\begin{array}{l}1.876^{* *} \\
(0.836)\end{array}$ & $\begin{array}{c}2.005^{*} \\
(1.168)\end{array}$ & $\begin{array}{c}1.904^{* *} \\
(0.835)\end{array}$ & $\begin{array}{c}2.058^{*} \\
(1.178)\end{array}$ \\
\hline Green EPC & $\begin{array}{c}0.357^{* * *} \\
(0.038)\end{array}$ & $\begin{array}{c}0.360^{* * *} \\
(0.067)\end{array}$ & & \\
\hline Orange EPC & $\begin{array}{c}0.118^{* * *} \\
(0.032)\end{array}$ & $\begin{array}{c}0.093^{*} \\
(0.055)\end{array}$ & & \\
\hline B & & & $\begin{array}{c}0.750^{* * *} \\
(0.086)\end{array}$ & $\begin{array}{c}0.637^{* * *} \\
(0.118)\end{array}$ \\
\hline $\mathrm{C}$ & & & $\begin{array}{c}0.318^{* * *} \\
(0.046)\end{array}$ & $\begin{array}{c}0.290^{* * *} \\
(0.084)\end{array}$ \\
\hline $\mathrm{D}$ & & & $\begin{array}{c}0.154^{\text {*** }} \\
(0.043)\end{array}$ & $\begin{array}{c}0.133^{*} \\
(0.077)\end{array}$ \\
\hline $\mathrm{E}$ & & & $\begin{array}{c}0.096^{* *} \\
(0.044)\end{array}$ & $\begin{array}{c}-0.020 \\
(0.077)\end{array}$ \\
\hline e & & & $\begin{array}{c}0.022 \\
(0.051)\end{array}$ & $\begin{array}{c}-0.075 \\
(0.090)\end{array}$ \\
\hline Year of construction dummies & & $\checkmark$ & & $\checkmark$ \\
\hline $\begin{array}{l}\text { Control variables (table D.10) and } \\
\text { socio-economic variables (table D.11) }\end{array}$ & $\checkmark$ & $\checkmark$ & $\checkmark$ & $\checkmark$ \\
\hline $\begin{array}{l}\text { Municipality dummies, month } \\
\text { dummies and year trend }\end{array}$ & $\checkmark$ & $\checkmark$ & $\checkmark$ & $\checkmark$ \\
\hline Observations & 13490 & 6112 & 13490 & 6112 \\
\hline Rho & -0.189 & 0.801 & -0.183 & 0.794 \\
\hline P-Value for Wald test & 0.000 & 0.000 & 0.000 & 0.000 \\
\hline
\end{tabular}

Exclusion restriction: share of electoral votes for green parties. Baseline is a rental advertisement for a dwelling disclosing a red rating in (1) and (2), or a G rating in (3) and (4). Robust standard errors in parentheses. Significance levels: ${ }^{*} p<0.10,{ }^{* *} p<0.05,{ }^{* * *} p<0.01$ 
Table D.10: The value of energy performance (control variables, outcome equation)

\begin{tabular}{|c|c|c|c|c|}
\hline & $(1)$ & $(2)$ & $(3)$ & $(4)$ \\
\hline & \multicolumn{4}{|c|}{ Log(real rent/sqm) } \\
\hline Log(surface) & $\begin{array}{c}-0.336^{* * *} \\
(0.010)\end{array}$ & $\begin{array}{c}-0.333^{* * *} \\
(0.017)\end{array}$ & $\begin{array}{c}-0.335^{* * *} \\
(0.010)\end{array}$ & $\begin{array}{c}-0.332^{* * *} \\
(0.018)\end{array}$ \\
\hline Nb bedrooms & $\begin{array}{c}0.057^{* * *} \\
(0.004)\end{array}$ & $\begin{array}{c}0.057^{* * *} \\
(0.007)\end{array}$ & $\begin{array}{c}0.057^{* * *} \\
(0.004)\end{array}$ & $\begin{array}{c}0.056^{* * *} \\
(0.007)\end{array}$ \\
\hline $\mathrm{Nb}$ bathrooms & $\begin{array}{c}0.005 \\
(0.005)\end{array}$ & $\begin{array}{c}0.045^{* * *} \\
(0.006)\end{array}$ & $\begin{array}{c}0.005 \\
(0.005)\end{array}$ & $\begin{array}{c}0.046^{* * *} \\
(0.006)\end{array}$ \\
\hline Dwelling type: house & $\begin{array}{c}0.065^{* * *} \\
(0.010)\end{array}$ & $\begin{array}{l}0.032^{* *} \\
(0.015)\end{array}$ & $\begin{array}{c}0.066^{* * *} \\
(0.010)\end{array}$ & $\begin{array}{c}0.032^{* *} \\
(0.015)\end{array}$ \\
\hline Brand new/renovated & $\begin{array}{c}0.028^{* * *} \\
(0.004)\end{array}$ & $\begin{array}{c}0.039^{* * *} \\
(0.007)\end{array}$ & $\begin{array}{c}0.027^{* * *} \\
(0.004)\end{array}$ & $\begin{array}{c}0.038^{* * *} \\
(0.007)\end{array}$ \\
\hline Equipped kitchen & $\begin{array}{c}0.007 \\
(0.005)\end{array}$ & $\begin{array}{c}0.000 \\
(0.006)\end{array}$ & $\begin{array}{c}0.007 \\
(0.004)\end{array}$ & $\begin{array}{l}-0.000 \\
(0.006)\end{array}$ \\
\hline Multilingual ad & $\begin{array}{c}0.024^{* * *} \\
(0.004)\end{array}$ & $\begin{array}{l}-0.007 \\
(0.006)\end{array}$ & $\begin{array}{c}0.023^{* * *} \\
(0.004)\end{array}$ & $\begin{array}{l}-0.006 \\
(0.006)\end{array}$ \\
\hline Number of words & $\begin{array}{c}0.000 \\
(0.000)\end{array}$ & $\begin{array}{c}-0.000^{* *} \\
(0.000)\end{array}$ & $\begin{array}{c}0.000 \\
(0.000)\end{array}$ & $\begin{array}{r}-0.000^{* *} \\
(0.000)\end{array}$ \\
\hline Access to open space & $\begin{array}{c}0.034^{* * *} \\
(0.004)\end{array}$ & $\begin{array}{c}0.045^{* * *} \\
(0.007)\end{array}$ & $\begin{array}{c}0.034^{* * *} \\
(0.004)\end{array}$ & $\begin{array}{c}0.044^{* * *} \\
(0.007)\end{array}$ \\
\hline Garage/parking & $\begin{array}{c}0.064^{* * *} \\
(0.006)\end{array}$ & $\begin{array}{c}0.047^{* * *} \\
(0.009)\end{array}$ & $\begin{array}{c}0.063^{* * *} \\
(0.006)\end{array}$ & $\begin{array}{c}0.047^{* * *} \\
(0.009)\end{array}$ \\
\hline Lift & $\begin{array}{c}-0.018^{* * *} \\
(0.005)\end{array}$ & $\begin{array}{c}-0.016^{* *} \\
(0.008)\end{array}$ & $\begin{array}{c}-0.018^{* * *} \\
(0.005)\end{array}$ & $\begin{array}{l}-0.015^{*} \\
(0.008)\end{array}$ \\
\hline Fully/partly furnished & $\begin{array}{c}0.232^{* * *} \\
(0.005)\end{array}$ & $\begin{array}{c}0.199^{* * *} \\
(0.007)\end{array}$ & $\begin{array}{c}0.232^{* * *} \\
(0.005)\end{array}$ & $\begin{array}{r}0.199^{* * *} \\
(0.007)\end{array}$ \\
\hline Short-term contract & $\begin{array}{l}0.040^{*} \\
(0.024)\end{array}$ & $\begin{array}{l}0.067^{* *} \\
(0.034)\end{array}$ & $\begin{array}{c}0.039 \\
(0.024)\end{array}$ & $\begin{array}{c}0.065^{*} \\
(0.033)\end{array}$ \\
\hline Real estate agency & $\begin{array}{l}-0.011 \\
(0.007)\end{array}$ & $\begin{array}{c}0.076^{* * *} \\
(0.016)\end{array}$ & $\begin{array}{l}-0.010 \\
(0.007)\end{array}$ & $\begin{array}{c}0.077^{* * *} \\
(0.016)\end{array}$ \\
\hline Luxury & $\begin{array}{c}0.191^{* * *} \\
(0.029)\end{array}$ & $\begin{array}{c}0.249^{* * *} \\
(0.050)\end{array}$ & $\begin{array}{c}0.193^{* * *} \\
(0.029)\end{array}$ & $\begin{array}{c}0.251^{* * *} \\
(0.050)\end{array}$ \\
\hline Main variables (see table 3 ) & $\checkmark$ & $\checkmark$ & $\checkmark$ & $\checkmark$ \\
\hline Socio-economic variables (see table D.11) & $\checkmark$ & $\checkmark$ & $\checkmark$ & $\checkmark$ \\
\hline Municipality dummies & $\checkmark$ & $\checkmark$ & $\checkmark$ & $\checkmark$ \\
\hline Year trend and month dummies & $\checkmark$ & $\checkmark$ & $\checkmark$ & $\checkmark$ \\
\hline Observations & 13490 & 6112 & 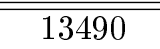 & 6112 \\
\hline
\end{tabular}

Baseline is a rental advertisement for a dwelling disclosing a red rating in (1) and (2), or a $\mathrm{G}$ rating in (3) and (4). Robust standard errors in parentheses. Significance levels: ${ }^{*} p<0.10,{ }^{* *} p<0.05,{ }^{* * *}$ $p<0.01$ 
Table D.11: The value of energy performance (socio-economic variables, outcome equation)

\begin{tabular}{|c|c|c|c|c|}
\hline & (1) & $(2)$ & $(3)$ & $(4)$ \\
\hline & \multicolumn{4}{|c|}{ Log(real rent/sqm) } \\
\hline \multirow[t]{2}{*}{ EU-15/OECD } & -0.021 & 0.006 & -0.021 & 0.007 \\
\hline & $(0.014)$ & $(0.022)$ & $(0.014)$ & $(0.022)$ \\
\hline \multirow[t]{2}{*}{ EU-New/Turkey } & 0.012 & 0.010 & 0.011 & 0.009 \\
\hline & $(0.011)$ & $(0.016)$ & $(0.011)$ & $(0.016)$ \\
\hline \multirow[t]{2}{*}{ Other nationality } & -0.010 & 0.016 & -0.008 & 0.018 \\
\hline & $(0.013)$ & $(0.020)$ & $(0.013)$ & $(0.020)$ \\
\hline \multirow[t]{2}{*}{ Nursery } & 0.101 & 0.121 & 0.114 & 0.135 \\
\hline & $(0.177)$ & $(0.257)$ & $(0.176)$ & $(0.256)$ \\
\hline \multirow[t]{2}{*}{ Primary school } & 0.085 & $0.468^{*}$ & 0.056 & $0.418^{*}$ \\
\hline & $(0.161)$ & $(0.244)$ & $(0.161)$ & $(0.244)$ \\
\hline \multirow[t]{2}{*}{ Kindergarten } & -0.196 & -0.104 & -0.200 & -0.109 \\
\hline & $(0.122)$ & $(0.168)$ & $(0.122)$ & $(0.168)$ \\
\hline \multirow[t]{2}{*}{ Revenue } & $0.000^{* * *}$ & 0.000 & $0.000^{* * *}$ & 0.000 \\
\hline & $(0.000)$ & $(0.000)$ & $(0.000)$ & $(0.000)$ \\
\hline \multirow[t]{2}{*}{ Unemployment } & 0.003 & 0.025 & 0.004 & 0.026 \\
\hline & $(0.020)$ & $(0.033)$ & $(0.020)$ & $(0.033)$ \\
\hline \multirow[t]{2}{*}{ Population density } & $0.000^{* * *}$ & -0.000 & $0.000^{* * *}$ & -0.000 \\
\hline & $(0.000)$ & $(0.000)$ & $(0.000)$ & $(0.000)$ \\
\hline \multirow[t]{2}{*}{ Office density } & 0.000 & -0.000 & 0.000 & -0.000 \\
\hline & $(0.000)$ & $(0.000)$ & $(0.000)$ & $(0.000)$ \\
\hline \multirow[t]{2}{*}{ Social housing } & $0.110^{* * *}$ & $0.098^{* *}$ & $0.111^{* * *}$ & $0.099^{* *}$ \\
\hline & $(0.026)$ & $(0.038)$ & $(0.026)$ & $(0.038)$ \\
\hline \multirow[t]{2}{*}{ Public transport } & 0.012 & 0.033 & 0.011 & 0.033 \\
\hline & $(0.019)$ & $(0.032)$ & $(0.019)$ & $(0.032)$ \\
\hline \multirow[t]{2}{*}{ Constant } & $110.230^{* * *}$ & 52.867 & $112.220^{* * *}$ & 52.704 \\
\hline & $(30.412)$ & $(45.581)$ & $(30.306)$ & $(45.467)$ \\
\hline Main variables (see table 3 ) & $\checkmark$ & $\checkmark$ & $\checkmark$ & $\checkmark$ \\
\hline Control variables (see table D.10) & $\checkmark$ & $\checkmark$ & $\checkmark$ & $\checkmark$ \\
\hline Municipality dummies & $\checkmark$ & $\checkmark$ & $\checkmark$ & $\checkmark$ \\
\hline Year trend and month dummies & $\checkmark$ & $\checkmark$ & $\checkmark$ & $\checkmark$ \\
\hline Observations & 13490 & 6112 & 13490 & 6112 \\
\hline
\end{tabular}

Baseline is a rental advertisement for a dwelling disclosing a red rating in (1) and (2), or a $\mathrm{G}$ rating in (3) and (4). Robust standard errors in parentheses. Significance levels: ${ }^{*} p<0.10,{ }^{* *} p<0.05,{ }^{* * *}$ $p<0.01$ 
Table D.12: The valuation of energy performance: alternative time specifications

\begin{tabular}{|c|c|c|c|c|}
\hline & $(1)$ & $(2)$ & $(3)$ & $(4)$ \\
\hline Outcome equation & & Log(real & ent/sqm) & \\
\hline Green EPC & $\begin{array}{c}0.037^{* * *} \\
(0.010)\end{array}$ & $\begin{array}{c}0.036^{* * *} \\
(0.010)\end{array}$ & & \\
\hline Orange EPC & $\begin{array}{c}0.010 \\
(0.008)\end{array}$ & $\begin{array}{c}0.009 \\
(0.008)\end{array}$ & & \\
\hline B & & & $\begin{array}{c}0.053^{* * *} \\
(0.016)\end{array}$ & $\begin{array}{c}0.052^{* * *} \\
(0.016)\end{array}$ \\
\hline $\mathrm{C}$ & & & $\begin{array}{l}0.020^{*} \\
(0.012)\end{array}$ & $\begin{array}{c}0.019 \\
(0.012)\end{array}$ \\
\hline $\mathrm{D}$ & & & $\begin{array}{c}0.001 \\
(0.012)\end{array}$ & $\begin{array}{c}-0.000 \\
(0.012)\end{array}$ \\
\hline $\mathrm{E}$ & & & $\begin{array}{c}-0.006 \\
(0.012)\end{array}$ & $\begin{array}{l}-0.007 \\
(0.012)\end{array}$ \\
\hline $\mathrm{F}$ & & & $\begin{array}{l}-0.025^{*} \\
(0.014) \\
\end{array}$ & $\begin{array}{l}-0.026^{*} \\
(0.014) \\
\end{array}$ \\
\hline Selection equation & & $\mathrm{EPC} \mathrm{di}$ & closure & \\
\hline greenvote & $\begin{array}{c}0.598 \\
(1.197)\end{array}$ & $\begin{array}{c}0.587 \\
(1.177)\end{array}$ & $\begin{array}{c}0.614 \\
(1.207)\end{array}$ & $\begin{array}{c}0.604 \\
(1.188)\end{array}$ \\
\hline Green EPC & $\begin{array}{c}0.355^{* * *} \\
(0.067)\end{array}$ & $\begin{array}{c}0.352^{* * *} \\
(0.067)\end{array}$ & & \\
\hline Orange EPC & $\begin{array}{c}0.087 \\
(0.055)\end{array}$ & $\begin{array}{c}0.086 \\
(0.055)\end{array}$ & & \\
\hline B & & & $\begin{array}{c}0.634^{* * *} \\
(0.118)\end{array}$ & $\begin{array}{c}0.639^{* * *} \\
(0.118)\end{array}$ \\
\hline $\mathrm{C}$ & & & $\begin{array}{c}0.290^{* * *} \\
(0.084)\end{array}$ & $\begin{array}{c}0.285^{* * *} \\
(0.084)\end{array}$ \\
\hline $\mathrm{D}$ & & & $\begin{array}{l}0.136^{*} \\
(0.077)\end{array}$ & $\begin{array}{c}0.137^{*} \\
(0.078)\end{array}$ \\
\hline $\mathrm{E}$ & & & $\begin{array}{c}-0.028 \\
(0.077)\end{array}$ & $\begin{array}{c}-0.033 \\
(0.077)\end{array}$ \\
\hline 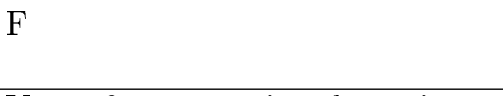 & & & $\begin{array}{c}-0.066 \\
(0.090)\end{array}$ & $\begin{array}{c}-0.069 \\
(0.090)\end{array}$ \\
\hline Year of construction dummies & $\checkmark$ & $\checkmark$ & $\checkmark$ & $\checkmark$ \\
\hline Year of publication dummies & $\checkmark$ & $\checkmark$ & $\checkmark$ & $\checkmark$ \\
\hline Month of publication dummies & $\checkmark$ & & $\checkmark$ & \\
\hline Quarter of publication dummies & & $\checkmark$ & & $\checkmark$ \\
\hline Observations & 6112 & 6112 & 6112 & 6112 \\
\hline Rho & 0.795 & 0.791 & 0.788 & 0.785 \\
\hline P-Value for Wald test & 0.000 & 0.000 & 0.000 & 0.000 \\
\hline
\end{tabular}

Exclusion restriction: share of electoral votes for green parties. Baseline is a rental advertisement for a dwelling disclosing a red rating in (1) and (2), or a $\mathrm{G}$ rating in (3) and (4). All specifications include all standard control and socio-economic variables of the baseline model and municipality dummies. Robust standard errors in parentheses. Significance levels: ${ }^{*} p<0.10,{ }^{* *} p<0.05,{ }^{* * *} p<0.01$ 
Table D.13: Ad duration under different levels of energy performance

\begin{tabular}{|c|c|c|c|c|}
\hline & (1) & $(2)$ & $(3)$ & $(4)$ \\
\hline Outcome equation & \multicolumn{4}{|c|}{ Log(real rent/sqm) } \\
\hline Green EPC & $\begin{array}{c}-7.508^{* * *} \\
(1.812)\end{array}$ & $\begin{array}{c}-6.574^{* *} \\
(3.185)\end{array}$ & & \\
\hline Orange EPC & $\begin{array}{c}-4.137^{* *} \\
(1.632)\end{array}$ & $\begin{array}{c}-5.773^{* *} \\
(2.855)\end{array}$ & & \\
\hline B & & & $\begin{array}{c}-6.706^{* *} \\
(3.397)\end{array}$ & $\begin{array}{l}-5.637 \\
(5.120)\end{array}$ \\
\hline $\mathrm{C}$ & & & $\begin{array}{c}-6.749^{* * *} \\
(2.220)\end{array}$ & $\begin{array}{l}-5.965 \\
(3.801)\end{array}$ \\
\hline $\mathrm{D}$ & & & $\begin{array}{c}-5.132^{* *} \\
(2.142)\end{array}$ & $\begin{array}{l}-5.755 \\
(3.702)\end{array}$ \\
\hline $\mathrm{E}$ & & & $\begin{array}{c}-0.966 \\
(2.249)\end{array}$ & $\begin{array}{l}-4.032 \\
(3.755)\end{array}$ \\
\hline $\mathrm{F}$ & & & $\begin{array}{c}1.881 \\
(2.790)\end{array}$ & $\begin{array}{c}1.710 \\
(4.808)\end{array}$ \\
\hline Selection equation & \multicolumn{4}{|c|}{ EPC disclosure } \\
\hline greenvote & $\begin{array}{c}3.842^{* * *} \\
(0.824)\end{array}$ & $\begin{array}{l}4.979^{* * *} \\
(1.254)\end{array}$ & $\begin{array}{c}3.857^{* * *} \\
(0.824)\end{array}$ & $\begin{array}{l}5.056^{* * *} \\
(1.253)\end{array}$ \\
\hline Green EPC & $\begin{array}{c}0.345^{* * *} \\
(0.037)\end{array}$ & $\begin{array}{c}0.423^{* * *} \\
(0.065)\end{array}$ & & \\
\hline Orange EPC & $\begin{array}{c}0.119^{* * *} \\
(0.031)\end{array}$ & $\begin{array}{c}0.177^{* * *} \\
(0.053)\end{array}$ & & \\
\hline B & & & $\begin{array}{l}0.712^{* * *} \\
(0.082)\end{array}$ & $\begin{array}{r}0.745^{* * *} \\
(0.115)\end{array}$ \\
\hline $\mathrm{C}$ & & & $\begin{array}{l}0.303^{* * *} \\
(0.045)\end{array}$ & $\begin{array}{c}0.384^{* * *} \\
(0.079)\end{array}$ \\
\hline $\mathrm{D}$ & & & $\begin{array}{c}0.141^{* * *} \\
(0.042)\end{array}$ & $\begin{array}{c}0.238^{* * *} \\
(0.073)\end{array}$ \\
\hline $\mathrm{E}$ & & & $\begin{array}{l}0.104^{* *} \\
(0.044)\end{array}$ & $\begin{array}{c}0.112 \\
(0.075)\end{array}$ \\
\hline 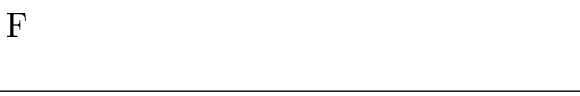 & & & $\begin{array}{c}0.012 \\
(0.051)\end{array}$ & $\begin{array}{l}-0.002 \\
(0.089)\end{array}$ \\
\hline Year of construction dummies & & $\checkmark$ & & $\checkmark$ \\
\hline Control and socio-economic variables & $\checkmark$ & $\checkmark$ & $\checkmark$ & $\checkmark$ \\
\hline $\begin{array}{l}\text { Municipality dummies, month } \\
\text { dummies and year trend }\end{array}$ & $\checkmark$ & $\checkmark$ & $\checkmark$ & $\checkmark$ \\
\hline Observations & 13490 & 6112 & 13490 & 6112 \\
\hline$\rho$ & -0.015 & -0.023 & -0.019 & -0.035 \\
\hline P-Value for Wald test & 0.415 & 0.283 & 0.271 & 0.102 \\
\hline
\end{tabular}

Exclusion restriction: share of electoral votes for green parties. Baseline is a rental advertisement for a dwelling disclosing a red rating in (1) and (2), or a $\mathrm{G}$ rating in (3) and (4). Robust standard errors in parentheses. Significance levels: ${ }^{*} p<0.10,{ }^{* *} p<0.05,{ }^{* * *} p<0.01$ 


\section{Appendix E. Additional results and robustness checks: Section 5}

Table E.14: 2SLS estimation: stage 0 (main control variables)

\begin{tabular}{|c|c|c|}
\hline & $\begin{array}{r}\text { Dep. var.: EP } \\
(1) \\
\text { Ads with orange EPC }\end{array}$ & $\begin{array}{l}\text { disclosure } \\
\text { Ads with red EPC }\end{array}$ \\
\hline Greenvote & $\begin{array}{c}5.093^{* * *} \\
(1.809)\end{array}$ & $\begin{array}{l}6.457^{* *} \\
(2.737)\end{array}$ \\
\hline $\log ($ surface $)$ & $\begin{array}{c}0.558^{* * *} \\
(0.141)\end{array}$ & $\begin{array}{c}0.554^{* * *} \\
(0.192)\end{array}$ \\
\hline $\mathrm{Nb}$ bedrooms & $\begin{array}{c}-0.119^{* *} \\
(0.060)\end{array}$ & $\begin{array}{l}-0.106 \\
(0.080)\end{array}$ \\
\hline Nb bathrooms & $\begin{array}{c}0.316^{* * *} \\
(0.062)\end{array}$ & $\begin{array}{l}0.159^{*} \\
(0.086)\end{array}$ \\
\hline Dwelling type: house & $\begin{array}{l}-0.135 \\
(0.143)\end{array}$ & $\begin{array}{c}0.028 \\
(0.179)\end{array}$ \\
\hline Brand new/renovated & $\begin{array}{c}0.026 \\
(0.070)\end{array}$ & $\begin{array}{l}-0.095 \\
(0.101)\end{array}$ \\
\hline Equipped kitchen & $\begin{array}{l}-0.065 \\
(0.074)\end{array}$ & $\begin{array}{l}-0.190 \\
(0.116)\end{array}$ \\
\hline Multilingual ad & $\begin{array}{c}-0.379^{* * *} \\
(0.060)\end{array}$ & $\begin{array}{c}-0.287^{* * *} \\
(0.093)\end{array}$ \\
\hline Number of words & $\begin{array}{c}-0.008^{* * *} \\
(0.001)\end{array}$ & $\begin{array}{c}0.000 \\
(0.002)\end{array}$ \\
\hline Access to open space & $\begin{array}{l}0.146^{* *} \\
(0.074)\end{array}$ & $\begin{array}{l}0.193^{*} \\
(0.113)\end{array}$ \\
\hline Garage/parking & $\begin{array}{c}0.003 \\
(0.081)\end{array}$ & $\begin{array}{c}0.050 \\
(0.131)\end{array}$ \\
\hline Lift & $\begin{array}{c}0.050 \\
(0.077)\end{array}$ & $\begin{array}{l}-0.004 \\
(0.133)\end{array}$ \\
\hline Fully/partly furnished & $\begin{array}{l}0.198^{* *} \\
(0.085)\end{array}$ & $\begin{array}{c}0.479^{* * *} \\
(0.132)\end{array}$ \\
\hline Short-term contract & $\begin{array}{c}0.051 \\
(0.384)\end{array}$ & $\begin{array}{c}0.347 \\
(0.504)\end{array}$ \\
\hline Real estate agency & $\begin{array}{c}1.094^{* * *} \\
(0.250)\end{array}$ & $\begin{array}{c}1.253^{* * *} \\
(0.388)\end{array}$ \\
\hline Luxury & $\begin{array}{l}-0.466^{*} \\
(0.257)\end{array}$ & $\begin{array}{l}-0.962 \\
(0.606)\end{array}$ \\
\hline $\begin{array}{l}\text { Control var. and socio-economic var. } \\
\text { Year of construction dummies } \\
\text { Municipality dummies, month } \\
\text { dummies and year trend }\end{array}$ & $\begin{array}{l}\checkmark \\
\checkmark \\
\checkmark\end{array}$ & $\begin{array}{l}\checkmark \\
\checkmark \\
\checkmark\end{array}$ \\
\hline $\begin{array}{l}\text { Observations } \\
\text { Pseudo R2 }\end{array}$ & $\begin{array}{l}3021 \\
0.24\end{array}$ & $\begin{array}{l}1067 \\
0.16\end{array}$ \\
\hline
\end{tabular}

Probit model (stage 0, which precedes the 2SLS analysis in order to obtain instrumental variable DiscHat). Dependent variable: EPC disclosure. Robust standard errors in parentheses. Spec (1) ads with disclosed orange EPC vs ads with hidden orange EPC (2) ads with disclosed red EPC vs ads with hidden red EPC. Significance levels: ${ }^{*} p<0.10,{ }^{* *} p<0.05,{ }^{* * *} p<0.01$ 
Table E.15: 2SLS estimation: stage 1 (main control variables)

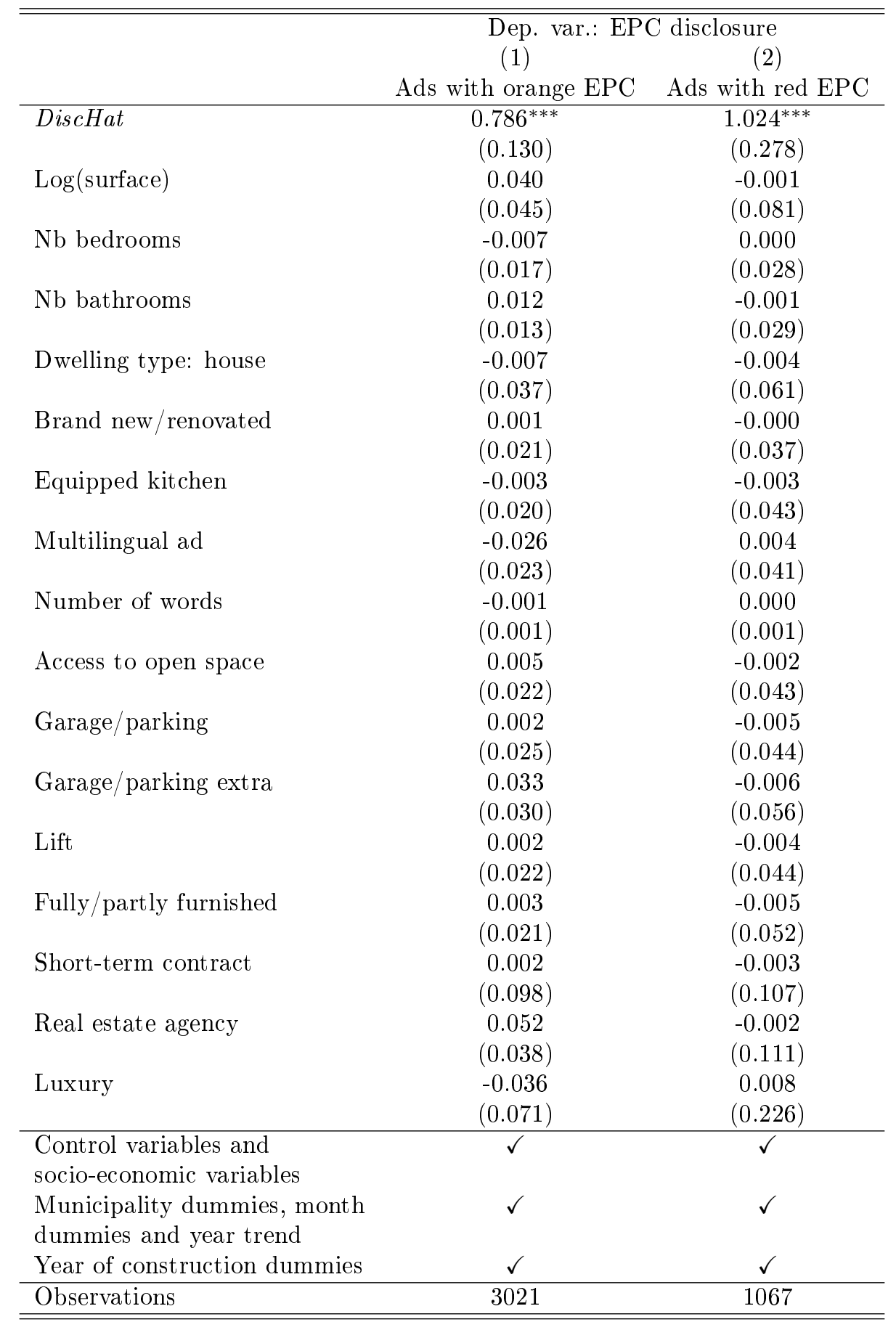

2SLS estimation (stage 1). Dependent variable: EPC disclosure. Robust standard errors in parentheses. Spec (1) ads with disclosed orange EPC vs ads with hidden orange EPC (2) ads with disclosed red EPC vs ads with hidden red EPC. Significance levels: ${ }^{*} p<0.10,{ }^{* *} p<0.05,{ }^{* * *} p<0.01$ 
Table E.16: The informational value of EPCs (2SLS estimation, stage 2, main control variables)

\begin{tabular}{|c|c|c|}
\hline & \multicolumn{2}{|c|}{ Dep. var.: Log(real rent/sqm) } \\
\hline & (1) & $(2)$ \\
\hline & Ads with orange EPC & Ads with red EPC \\
\hline \multirow[t]{2}{*}{ Disclosed EPC } & 0.086 & $-0.265^{* *}$ \\
\hline & $(0.067)$ & $(0.130)$ \\
\hline \multirow[t]{2}{*}{$\log ($ surface) } & $-0.414^{* * *}$ & $-0.409^{* * *}$ \\
\hline & $(0.021)$ & $(0.039)$ \\
\hline \multirow[t]{2}{*}{$\mathrm{Nb}$ bedrooms } & $0.073^{* * *}$ & $0.056^{* * *}$ \\
\hline & $(0.008)$ & $(0.013)$ \\
\hline \multirow[t]{2}{*}{$\mathrm{Nb}$ bathrooms } & $0.028^{* * *}$ & $0.063^{* * *}$ \\
\hline & $(0.007)$ & $(0.015)$ \\
\hline \multirow{2}{*}{ Dwelling type: house } & $0.077^{* * *}$ & $0.130^{* * *}$ \\
\hline & $(0.017)$ & $(0.030)$ \\
\hline \multirow[t]{2}{*}{ Brand new/renovated } & $0.050^{* * *}$ & 0.023 \\
\hline & $(0.008)$ & $(0.016)$ \\
\hline \multirow[t]{2}{*}{ Equipped kitchen } & 0.005 & -0.013 \\
\hline & $(0.007)$ & $(0.019)$ \\
\hline \multirow[t]{2}{*}{ Multilingual ad } & $0.033^{* * *}$ & -0.025 \\
\hline & $(0.010)$ & $(0.019)$ \\
\hline \multirow[t]{2}{*}{ Number of words } & 0.000 & $0.001^{* *}$ \\
\hline & $(0.000)$ & $(0.000)$ \\
\hline \multirow[t]{2}{*}{ Access to open space } & $0.032^{* * *}$ & $0.037^{* *}$ \\
\hline & $(0.008)$ & $(0.018)$ \\
\hline \multirow[t]{2}{*}{ Garage/parking } & $0.048^{* * *}$ & $0.052^{* *}$ \\
\hline & $(0.010)$ & $(0.021)$ \\
\hline \multirow[t]{2}{*}{ Lift } & $-0.023^{* * *}$ & $-0.048^{* *}$ \\
\hline & $(0.008)$ & $(0.021)$ \\
\hline \multirow[t]{2}{*}{ Fully/partly furnished } & $0.181^{* * *}$ & $0.219^{* * *}$ \\
\hline & $(0.008)$ & $(0.026)$ \\
\hline \multirow[t]{2}{*}{ Short-term contract } & 0.054 & 0.101 \\
\hline & $(0.048)$ & $(0.065)$ \\
\hline \multirow[t]{2}{*}{ Real estate agency } & $0.047^{*}$ & 0.073 \\
\hline & $(0.024)$ & $(0.059)$ \\
\hline \multirow[t]{2}{*}{ Luxury } & $0.180^{* * *}$ & 0.012 \\
\hline & $(0.064)$ & $(0.073)$ \\
\hline Socio-economic variables, municipality-level & $\checkmark$ & $\checkmark$ \\
\hline $\begin{array}{l}\text { Municipality dummies, month } \\
\text { dummies and year trend }\end{array}$ & $\checkmark$ & $\checkmark$ \\
\hline Year of construction dummies & $\checkmark$ & $\checkmark$ \\
\hline $\mathrm{R} 2$ & 0.603 & 0.294 \\
\hline Observations & 3021 & 1067 \\
\hline
\end{tabular}

2SLS estimation (stage 2). Dependent variable: log(real rent/sqm). Robust standard errors in parentheses. Spec (1) ads with disclosed orange EPC vs ads with hidden orange EPC (2) ads with disclosed red EPC vs ads with hidden red EPC. Significance levels: ${ }^{*} p<0.10,{ }^{* *} p<0.05,{ }^{* * *} p<0.01$ 
Table E.17: Montiel-Pflueger robust weak instrument test, based on results from stage 1 of 2SLS estimation

\begin{tabular}{lcc}
\hline $\begin{array}{l}\text { Specification in stage 1 } \\
\text { (cf. table E.15) }\end{array}$ & $\begin{array}{c}(1) \\
\text { Orange EPCs }\end{array}$ & $\begin{array}{c}(2) \\
\text { Red EPCs }\end{array}$ \\
\hline \hline Effective F statistic: & 36.469 & 13.529 \\
Confidence level alpha: & $5 \%$ & $5 \%$ \\
\hline \hline Critical Values & & \\
\hline$\%$ of Worst Case Bias & \multicolumn{2}{c}{37.418} \\
$\tau=5 \%$ & \multicolumn{2}{c}{23.109} \\
$\tau=10 \%$ & \multicolumn{2}{c}{15.062} \\
$\tau=20 \%$ & \multicolumn{2}{c}{12.039} \\
$\tau=30 \%$ & \\
\hline
\end{tabular}


Table E.18: The valuation of hidden EPC ratings (main variables of interest)

\begin{tabular}{|c|c|c|}
\hline & \multicolumn{2}{|c|}{$\log ($ real rent $/ \mathrm{sqm})$} \\
\hline Baseline & Red EPC & G-rated EPC \\
\hline Green EPC & $\begin{array}{c}0.001 \\
(0.013)\end{array}$ & \\
\hline Orange EPC & $\begin{array}{c}0.017 \\
(0.010)\end{array}$ & \\
\hline $\mathrm{B}$ & & $\begin{array}{c}0.013 \\
(0.030)\end{array}$ \\
\hline $\mathrm{C}$ & & $\begin{array}{c}0.005 \\
(0.016)\end{array}$ \\
\hline $\mathrm{D}$ & & $\begin{array}{c}0.031^{* *} \\
(0.015)\end{array}$ \\
\hline $\mathrm{E}$ & & $\begin{array}{c}0.008 \\
(0.014)\end{array}$ \\
\hline $\mathrm{F}$ & & $\begin{array}{c}0.006 \\
(0.016)\end{array}$ \\
\hline $\log ($ surface $)$ & $\begin{array}{c}-0.449^{* * *} \\
(0.024)\end{array}$ & $\begin{array}{c}-0.450^{* * *} \\
(0.024)\end{array}$ \\
\hline $\mathrm{Nb}$ bedrooms & $\begin{array}{c}0.059^{* * *} \\
(0.010)\end{array}$ & $\begin{array}{c}0.059^{* * *} \\
(0.010)\end{array}$ \\
\hline Nb bathrooms & $\begin{array}{c}0.015 \\
(0.010)\end{array}$ & $\begin{array}{c}0.015 \\
(0.010)\end{array}$ \\
\hline Dwelling type: house & $\begin{array}{c}0.146^{* * *} \\
(0.028)\end{array}$ & $\begin{array}{c}0.146^{* * *} \\
(0.028)\end{array}$ \\
\hline Brand new/renovated & $\begin{array}{c}0.051^{* * *} \\
(0.010)\end{array}$ & $\begin{array}{c}0.051^{* * *} \\
(0.010)\end{array}$ \\
\hline Equipped kitchen & $\begin{array}{c}0.007 \\
(0.010)\end{array}$ & $\begin{array}{c}0.006 \\
(0.010)\end{array}$ \\
\hline Multilingual ad & $\begin{array}{c}0.004 \\
(0.010)\end{array}$ & $\begin{array}{c}0.004 \\
(0.010)\end{array}$ \\
\hline Number of words & $\begin{array}{l}0.000^{*} \\
(0.000)\end{array}$ & $\begin{array}{l}0.000^{*} \\
(0.000)\end{array}$ \\
\hline Access to open space & $\begin{array}{c}0.023^{* *} \\
(0.009)\end{array}$ & $\begin{array}{c}0.022^{* *} \\
(0.009)\end{array}$ \\
\hline Garage/parking & $\begin{array}{c}0.047^{* * *} \\
(0.012)\end{array}$ & $\begin{array}{c}0.048^{* * *} \\
(0.012)\end{array}$ \\
\hline Lift & $\begin{array}{c}-0.056^{* * *} \\
(0.010)\end{array}$ & $\begin{array}{c}-0.055^{* * *} \\
(0.010)\end{array}$ \\
\hline Fully/partly furnished & $\begin{array}{c}0.174^{* * *} \\
(0.015)\end{array}$ & $\begin{array}{c}0.175^{* * *} \\
(0.015)\end{array}$ \\
\hline Short-term contract & $\begin{array}{c}0.041 \\
(0.077)\end{array}$ & $\begin{array}{c}0.042 \\
(0.078)\end{array}$ \\
\hline Real estate agency & $\begin{array}{c}0.055 \\
(0.047)\end{array}$ & $\begin{array}{c}0.059 \\
(0.047)\end{array}$ \\
\hline Luxury & $\begin{array}{c}0.263^{* * *} \\
(0.086)\end{array}$ & $\begin{array}{c}0.259^{* * *} \\
(0.086)\end{array}$ \\
\hline Control var. and socio-economic var. & $\checkmark$ & $\checkmark$ \\
\hline Municipality dummies, month dummies, year trend & $\checkmark$ & $\checkmark$ \\
\hline Year of construction dummies & $\checkmark$ & $\checkmark$ \\
\hline $\mathrm{R} 2$ & 0.585 & 0.586 \\
\hline Observations & 1630 & 1630 \\
\hline
\end{tabular}

Dependent variable: $\log$ (real rent/sqm). Estimation: OLS. Sample contains rental ads with hidden EPC ratings. Note that all A-rated EPCs are disclosed, hence they are excluded from both specifications. Robust standard errors in parentheses. Significance levels: ${ }^{*} p<0.10,{ }^{* *} p<0.05,{ }^{* * *} p<0.01$ 
Table E.19: The impact of EPC disclosure on ad duration (main variables of interest)

\begin{tabular}{|c|c|c|}
\hline & $\begin{array}{c}(1) \\
\text { Ad durat }\end{array}$ & $\begin{array}{c}(2) \\
\text { on (days) }\end{array}$ \\
\hline Disclosed EPC & $\begin{array}{c}-8.835 \\
(24.260)\end{array}$ & $\begin{array}{c}-27.626 \\
(37.662)\end{array}$ \\
\hline Log(surface) & $\begin{array}{c}24.261^{* * *} \\
(6.556)\end{array}$ & $\begin{array}{c}38.776^{* * *} \\
(10.667)\end{array}$ \\
\hline $\mathrm{Nb}$ bedrooms & $\begin{array}{l}-1.862 \\
(2.315)\end{array}$ & $\begin{array}{l}-4.665 \\
(3.871)\end{array}$ \\
\hline Nb bathrooms & $\begin{array}{c}1.306 \\
(2.060)\end{array}$ & $\begin{array}{c}5.403 \\
(4.318)\end{array}$ \\
\hline Dwelling type: house & $\begin{array}{c}-6.582 \\
(5.589)\end{array}$ & $\begin{array}{r}-14.028 \\
(8.575)\end{array}$ \\
\hline Brand new/renovated & $\begin{array}{l}-1.266 \\
(2.806)\end{array}$ & $\begin{array}{c}13.953^{* * *} \\
(4.671)\end{array}$ \\
\hline Equipped kitchen & $\begin{array}{c}-4.349^{*} \\
(2.533)\end{array}$ & $\begin{array}{c}3.321 \\
(5.325)\end{array}$ \\
\hline Multilingual ad & $\begin{array}{c}4.202 \\
(3.898)\end{array}$ & $\begin{array}{l}-9.521 \\
(6.178)\end{array}$ \\
\hline Number of words & $\begin{array}{c}-0.045 \\
(0.074)\end{array}$ & $\begin{array}{c}-0.015 \\
(0.078)\end{array}$ \\
\hline Access to open space & $\begin{array}{c}2.700 \\
(3.063)\end{array}$ & $\begin{array}{c}2.105 \\
(4.884)\end{array}$ \\
\hline Garage/parking & $\begin{array}{c}3.908 \\
(3.675)\end{array}$ & $\begin{array}{c}0.375 \\
(5.807)\end{array}$ \\
\hline Lift & $\begin{array}{c}3.907 \\
(3.190)\end{array}$ & $\begin{array}{l}-3.662 \\
(6.198)\end{array}$ \\
\hline Fully/partly furnished & $\begin{array}{l}5.278^{*} \\
(2.962)\end{array}$ & $\begin{array}{l}12.793^{*} \\
(7.325)\end{array}$ \\
\hline Short-term contract & $\begin{array}{c}-29.547^{* * *} \\
(10.423)\end{array}$ & $\begin{array}{c}-34.155^{* *} \\
(14.792)\end{array}$ \\
\hline Real estate agency & $\begin{array}{c}8.159 \\
(8.981)\end{array}$ & $\begin{array}{c}1.463 \\
(17.194)\end{array}$ \\
\hline Luxury & $\begin{array}{c}-5.601 \\
(12.645)\end{array}$ & $\begin{array}{c}6.495 \\
(34.032)\end{array}$ \\
\hline Socio-economic variables, municipality-level & $\checkmark$ & $\checkmark$ \\
\hline $\begin{array}{l}\text { Municipality dummies, month } \\
\text { dummies and year trend }\end{array}$ & $\checkmark$ & $\checkmark$ \\
\hline Year of construction dummies & $\checkmark$ & $\checkmark$ \\
\hline $\mathrm{R} 2$ & 0.067 & 0.096 \\
\hline Observations & 2881 & 997 \\
\hline
\end{tabular}

2SLS estimation (stage 2). Dependent variable: advertisement duration (days). Robust standard errors in parentheses. Spec (1) ads with disclosed orange EPC vs ads with hidden orange EPC (2) ads with disclosed red EPC vs ads with hidden red EPC. Significance levels: ${ }^{*} p<0.10,{ }^{* *} p<0.05,{ }^{* * *} p<0.01$ 